\title{
Synthesis and Swelling Behaviors of Hydrogels Containing LiMA Groups and its Use in Cu(II) Adsorption from Aqueous Solution
}

\author{
Cemal Özeroğlu ${ }^{1, *(\mathbb{D})}$, Öznur Korkmaz ${ }^{1}$ \\ 1 Istanbul University-Cerrahpaşa Faculty of Engineering Department of Chemistry 34320 Avcılar-Istanbul, Turkey; \\ ozeroglu@iuc.edu.tr (C.O.); \\ * Correspondence: ozeroglu@iuc.edu.tr (C.O.);
}

Scopus Author ID 56531879900

Received: 24.05.2021; Revised: 1.07.2021; Accepted: 5.07.2021; Published: 10.08.2021

\begin{abstract}
In this paper, cerium sulfate tetrahydrate (Ce(IV)) dissolved in acid-aqueous medium and mercaptosuccinic acid (MSA) redox couple was used to synthesize the crosslinked copolymer of acrylamide (AAm), lithium methacrylate (LiMA), and N,N'-methylene bisacrylamide (MBAAm) in the presence of ethylenediaminetetraacetic acid tetrasodium salt (EDTANa 4 ). The effects of various mole amounts of AAm and LiMA at constant crosslinker concentration and mole amounts of total monomer/MBAAm at constant amounts of AAm and LiMA on the swelling behaviors and swelling kinetics of synthesized hydrogels were investigated in distilled water. The use of hydrogel, including lithium methacrylate ionic groups, for the removal of copper ions from aqueous solutions was examined by using the batch adsorption method. In the adsorption process of copper ions on hydrogels containing LiMA groups, the effects of parameters such as the amount of hydrogel, initial $\mathrm{Cu}$ (II) concentration, adsorption time, and $\mathrm{pH}$ of solution were investigated.
\end{abstract}

Keywords: Ionic hydrogel; swelling kinetics; adsorption of copper ions; lithium methacrylate.

(C) 2021 by the authors. This article is an open-access article distributed under the terms and conditions of the Creative Commons Attribution (CC BY) license (https://creativecommons.org/licenses/by/4.0/).

\section{Introduction}

Hydrogels with the three-dimensional network are synthesized by copolymerization of monomers in the presence of a crosslinker [1-5]. They can swell or shrink according to their molecular structures and environmental changes such as temperature, $\mathrm{pH}$, electrical field, $\mathrm{UV}$ or visible light radiation, solvent composition, salt concentrations, and types of surfactants [610]. Because of environmental sensitivity and unique structure, polymer hydrogels can be used in various areas such as drug delivery systems, tissue engineering, wound healing, separation techniques in biotechnology, and environment processing agricultural products, sensors, and actuators [11-17].

$\mathrm{pH}$-sensitive hydrogels can be synthesized by adding pendant acidic or basic functional groups to the polymer backbone and can be used in application areas such as drug delivery and separation/preconcentration of dye or metal ion from aqueous or waste solutions. In addition, a sufficient number of acidic or basic monomers can be incorporated into the hydrogel network to adjust the swelling behaviors of hydrogels in acidic or basic conditions [14-20].

Synthesis and swelling behaviors of hydrogels have been investigated widely in previous investigations [21-26]. In the synthesis of gel particles, the initiator systems of sodium persulfate (SPS), potassium persulfate (KPS), or ammonium persulfate (APS) with or without 
$\mathrm{N}, \mathrm{N}, \mathrm{N}$ ',N'-tetramethylenediamine (TEMED) were generally used at high temperature or room temperature polymerization of monomer or copolymerization of monomers in the presence of crosslinker [27-32]. Moreover, the suitable organic compounds bearing thiol, hydroxyl, carboxyl, or amine functional groups as reducing agents and ceric salts as oxidants have been used to initiate polymerization or copolymerization of vinyl monomers [33-39]. However, the initiator systems of ceric salt as oxidant and organic reducing agent bearing thiol and carboxyl functional groups in the presence of ethylenediaminetetraacetic acid tetrasodium salt (EDTANa4) are suitable new sources to initiate copolymerization of vinyl monomers by using N,N'-methylene bisacrylamide (MBAAm) as crosslinker at low temperatures [40].

Radioactive and toxic metal ions in waste solutions are a global problem due to their toxic or radioactive effects on humans, animals, and plants. For this reason, the improvement of effective and low-cost methods for the removal and recovery of these metal ions is of great importance to avoid decreasing contaminants in waste solutions or wastes. To remove toxic or radioactive metal ions from aqueous and waste solutions, chemical precipitation, membrane extraction, coagulation, ion exchange, and adsorption methods have been used widely in industry and scientific investigations. In recent years, non-swelling crosslinked copolymers containing carboxylate functional groups and swelling crosslinked copolymers (hydrogels) bearing ionic functional groups have been synthesized and used for the removal of toxic and radioactive metal ions or textile dyes from aqueous or waste solutions, and these investigations have continued to attract considerable attention [41-44]. Copolymeric hydrogels of acrylamide with some acidic monomers were synthesized to separate dyes or toxic metal ions from aqueous or waste solutions [45-50]. However, the crosslinked copolymers of acrylamide, lithium methacrylate, and N.N'-methylene bisacrylamide were not used to absorb copper ions from aqueous solutions.

Copper used in the drive moving parts, brake linings, metal plating, pulp and paper industry, fertilizer mills, fungicides, insecticides, etc., is considered a trace element at low doses because the human body can regulate the trace level hemostatically. However, copper ions at high concentrations in the human body indicate a toxic effect due to their tendency to accumulate in the vital organ and harmful impact on the environment because they are nonbiodegradable, causing many diseases and disorders [51-55]. For this reason, the removal of copper ions as heavy metal ions on crosslinked copolymer (hydrogel) bearing lithium methacrylate functional groups from aqueous solution has been purposed.

In this paper, hydrogels of AAm, LiMA, and MBAAm prepared in the presence of EDTANa4 were synthesized by using the redox couple of Ce(IV) as oxidant dissolved in sulfuric acid medium and MSA as reducing agent. The dependence of swelling behaviors and kinetics of synthesized hydrogels in distilled water to the mole amounts of LiMA and AAm at constant crosslinker concentration and mole ratios of total monomer/crosslinker at different crosslinker concentrations was investigated. Equilibrium swelling values obtained from swelling curves and kinetic parameters of $\mathrm{k}$ and $\mathrm{n}$ values in the swelling kinetic equation were determined. The hydrogel with $77.7 \mathrm{~g} \mathrm{H}_{2} \mathrm{O} / \mathrm{g}$ dry gel of equilibrium swelling value was used to remove $\mathrm{Cu}$ (II) from the aqueous solution. The effects of adsorption parameters such as the amount of hydrogel, initial copper concentration, adsorption time, and $\mathrm{pH}$ of solution for removing copper ions from aqueous solution were investigated. The removal of copper ions from an aqueous solution was investigated. 


\section{Materials and Methods}

\subsection{Materials.}

Acrylamide (Merck), lithium hydroxide (Merck), methacrylic acid (Merck), N,N'methylene bisacrylamide (Fluka), mercaptosuccinic acid (Merck), cerium(IV) sulfate tetrahydrate (Merck), ethylenediamine tetraacetic acid tetrasodium salt (BASF) were used further treatment. Acrylamide, methacrylic acid, lithium methacrylate (ionic monomer, IM), N,N'-methylene bisacrylamide, mercaptosuccinic acid, cerium(IV) sulfate tetrahydrate, ethylenediamine tetraacetic acid tetrasodium salt were denoted as AAm, MA, LiMA, MBAAm, MSA, Ce(IV), EDTANa4, respectively.

\subsection{Preparation of ionic monomer.}

Equal molar solutions of $\mathrm{LiOH}$ and MA were mixed to prepare the amount of necessary solution of LiMA or IM to use in the hydrogel synthesis of AAm, LiMA, and MBAAm in the presence of MSA and EDTANa 4 by using $\mathrm{Ce}(\mathrm{IV})$ as oxidant dissolved in $\mathrm{H}_{2} \mathrm{SO}_{4}$ aqueous solution.

\subsection{Syntheses of $P(A A m-M B A A m)$ and $P(A A m-L i M A-M B A A m)$.}

AAm-MBAAm and AAm-LiMA-MBAAm copolymers were synthesized in a beaker of $250 \mathrm{~mL}$ containing a magnetic stirrer by adding $\mathrm{Ce}(\mathrm{IV})$ solution prepared in the solution of $\mathrm{H}_{2} \mathrm{SO}_{4}$ to the solution of the calculated amounts of AAm, MBAAm, MSA, and EDTANA4 without and with LiMA, respectively. $100 \mathrm{~mL}$ aqueous solution comprising $1.415 \mathrm{~g}$ of cerium sulfate tetrahydrate and $1.4 \mathrm{~mL} 98 \% \mathrm{H}_{2} \mathrm{SO}_{4}$ was prepared as oxidant solution used for initiating copolymerization. The solution volume of the oxidant was kept constant at 4-6 $\mathrm{mL}$ in a copolymerization reaction. The total volume of each crosslinking copolymerization reaction was approximately $100 \mathrm{~mL}$. Before starting the copolymerization reaction, the aqueous copolymerization solution of AAm, MBAAm, MSA, and EDTANa4 with and without LiMA were mixed by using a magnetic stirrer for about 10 minutes at a constant temperature of $30^{\circ} \mathrm{C}$. Then 4-6 $\mathrm{mL}$ of acidic oxidant solution was added to this mixture by using a burette. The formed crosslinked copolymers (hydrogels) were stored in a water bath for about 24 hours at $25^{\circ} \mathrm{C}$ to achieve a complete copolymerization. The synthesized hydrogels were cut into 3-4 $\mathrm{mm}$ length pieces, immersed in excess of distilled water for $4 \mathrm{~h}$ to remove unreacted compounds, and dried at $60^{\circ} \mathrm{C}$ in an oven.

\subsection{Determination of swelling behaviors and kinetics of hydrogels.}

A certain amount of dried hydrogel was immersed in distilled water to study the swelling behaviors of hydrogels in distilled water. The swelling behaviors and kinetics of hydrogels were investigated by mass measurement against time. The effect of reaction chemicals such as acrylamide, crosslinker, and ionic monomer on swelling behaviors and kinetics of the synthesized hydrogels were investigated in distilled water.

Swelling ratios (St) and equilibrium swelling ratios (Seq) of synthesized hydrogels of AAm-MBAAm and AAm-MBAAm-LiMA in distilled water were calculated by using equations (1) and (2), respectively. 


$$
\begin{aligned}
& \mathrm{S}_{\mathrm{t}}=\frac{\mathrm{m}_{\mathrm{t}}-\mathrm{m}_{0}}{\mathrm{~m}_{0}} \\
& \mathrm{~S}_{\mathrm{eq}}=\frac{\mathrm{m}_{\mathrm{eq}}-\mathrm{m}_{0}}{\mathrm{~m}_{0}}
\end{aligned}
$$

where $S_{t}$ and $S_{\text {eq }}$ denote the average swelling and equilibrium swelling ratios of hydrogel, respectively, in terms of $\mathrm{g} \mathrm{H}_{2} \mathrm{O} / \mathrm{g}$ dried gel. The experimental results have been obtained from triplicate measurements. The $\mathrm{m}_{\mathrm{t}}$ and $\mathrm{m}_{0}$ are the weight of swollen gel at time $\mathrm{t}$ and the weight of dried gel at the initial time, respectively. The meq is the weight of swollen gel at equilibrium.

Swelling kinetics of crosslinked copolymers of AAm and AAm-LiMA in the presence of MBAAm by using MSA-Ce(IV) redox initiator system was examined by the Peppas kinetic formulae (3) [56-59].

$$
\frac{\mathrm{S}_{\mathrm{t}}}{\mathrm{S}_{\mathrm{eq}}}=\mathrm{kt}^{\mathrm{n}}
$$

The linearized form of equation (3) can be written as equation (4),

$$
\ln \left(S_{t} / S_{e q}\right)=\ln k+n \ln t
$$

where $S_{\mathrm{t}}$ and $S_{\text {eq }}$ represent the average swelling and equilibrium swelling ratios of hydrogel, respectively, in terms of $\mathrm{g} \mathrm{H}_{2} \mathrm{O} / \mathrm{g}$ dried gel. $\mathrm{k}$ and $\mathrm{n}$ are constants in the swelling kinetic equation. The values of exponent $\mathrm{n}$ are dependent on the amount of ionic groups in hydrogel and the crosslinking degree of the hydrogel. This equation is valid in the swelling ratio less than $60 \%$ [58-59]. Using this criterion, the exponent, $\mathrm{n}$, and $\mathrm{k}$ values are determined from the slope and intercept by plotting $\ln \left(\mathrm{S}_{\mathrm{t}} / \mathrm{S}_{\mathrm{eq}}\right)$ versus $\ln \mathrm{t}$, respectively.

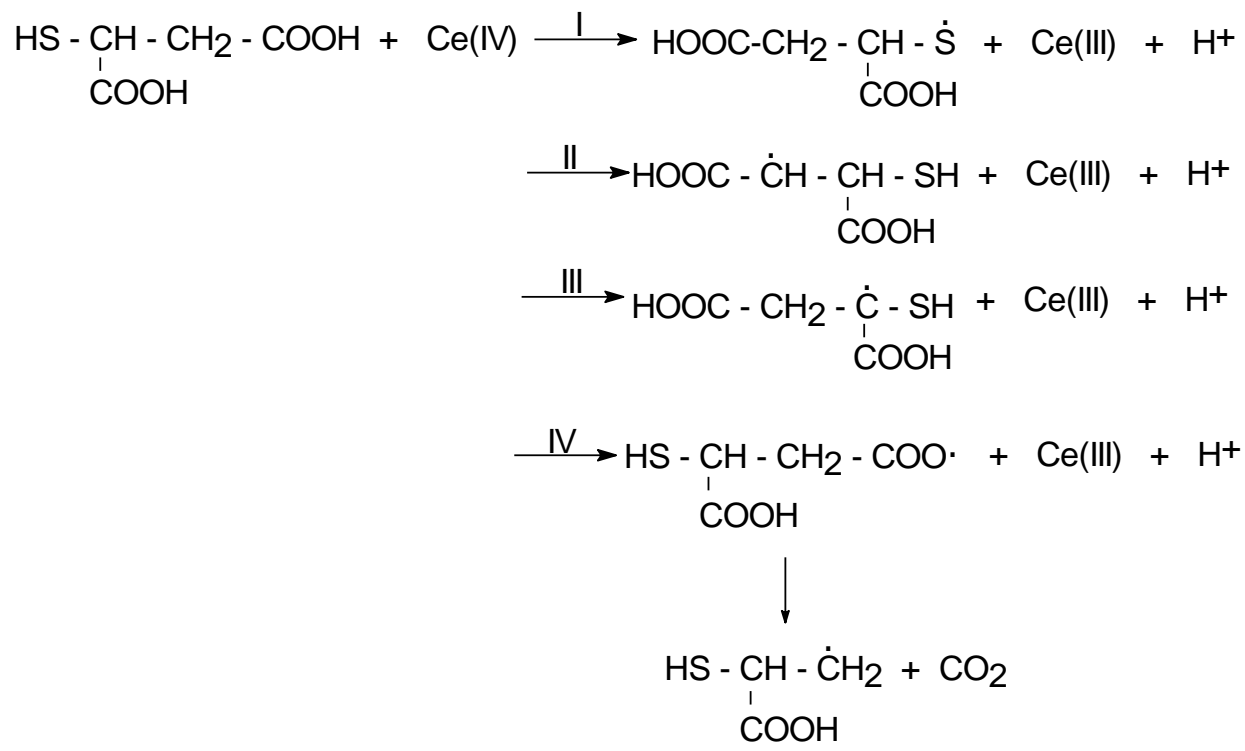

Scheme 1. Radical formation reactions between MSA and Ce(IV) in aqueous acid medium.

\subsection{Characterization of synthesized hydrogels.}

The redox reaction between MSA and Ce(IV) dissolved in a sulfuric acid solution leads to the formation of radicals by one-electron transfer. Radical formation reaction between MSA 
and $\mathrm{Ce}(\mathrm{IV})$ in an acid-aqueous medium is illustrated in Scheme 1. Because of low S-H bonding energy, free radical formation in reaction $I$ in Scheme 1 is more suitable than other reactions shown in scheme 1 to initiate crosslinking polymerization of AAm and MBAAm or AAm, MBAAm, and LiMA as explained in previous studies [36-37, 39-40]. Chemical mechanisms of the formation in the crosslinking copolymerization of AAm-MBAAm and AAm-LiMAMBAAm are shown in Schemes 2 and 3, respectively.

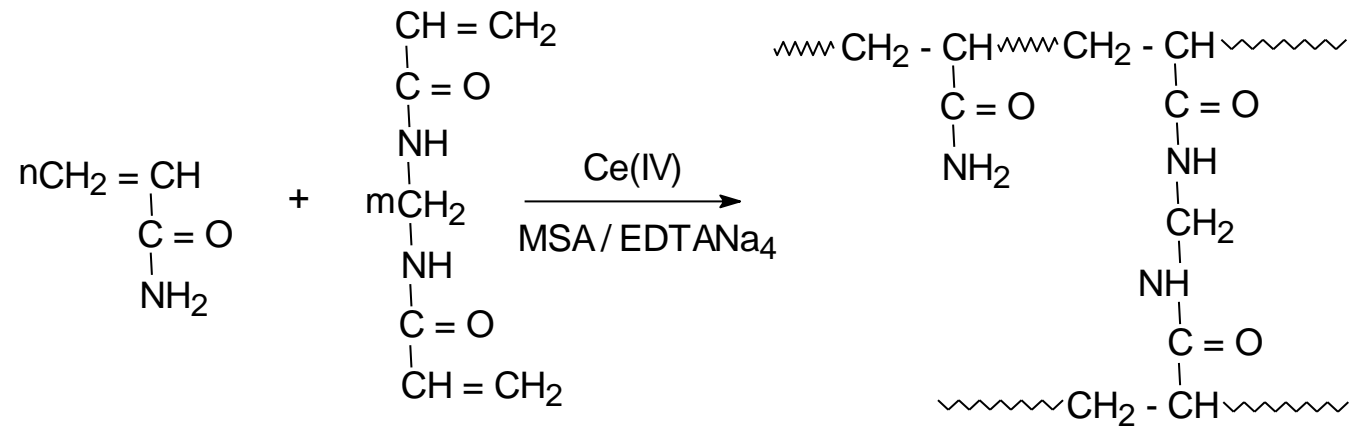

Scheme 2. The structure of chemical formation of AAm-MBAAm hydrogel.

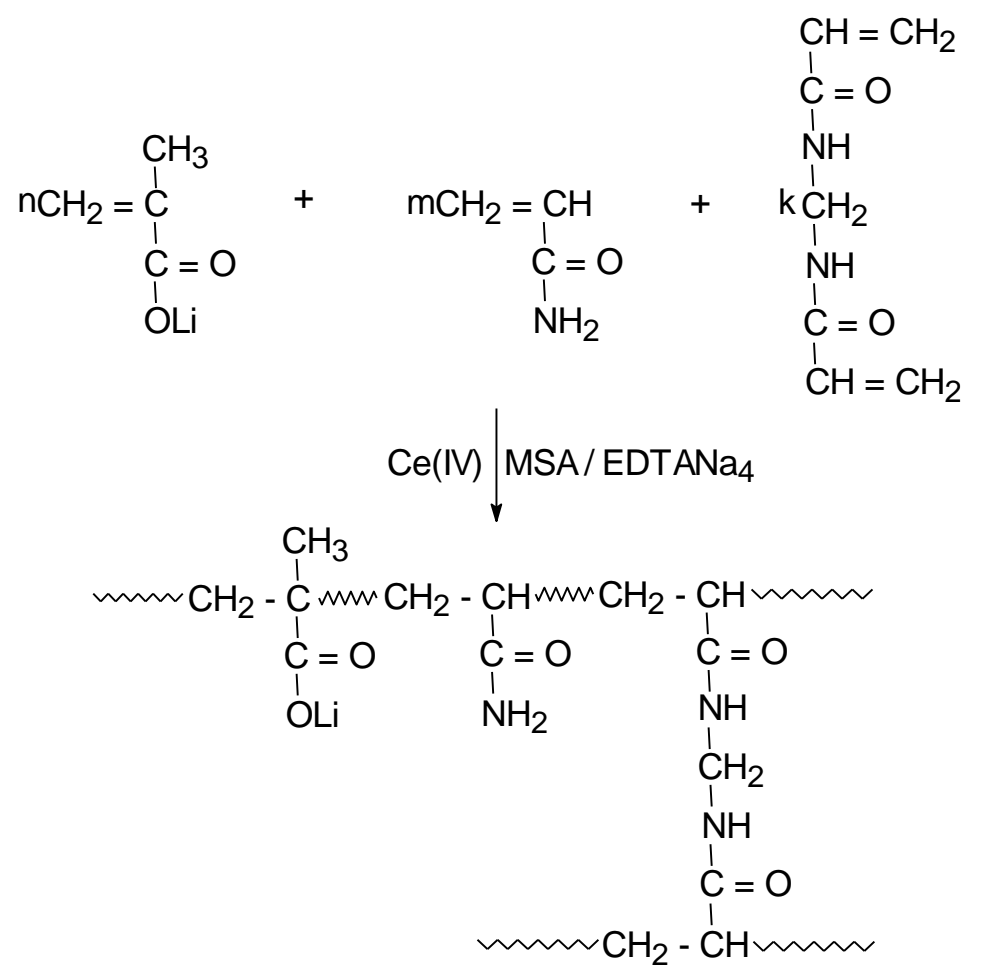

Scheme 3. The chemical formation mechanism of P(AAm-LiMA-MBAAm).

FT-IR analyses of both AAm-MBAAm and AAm-LiMA-MBAAm gels were performed on an ATI Unicam Mattson 1000 spectrometer by using the $\mathrm{KBr}$ disk method. For this purpose, the pellet of about $300 \mathrm{mg} \mathrm{KBr}$ powder and $8 \mathrm{mg}$ gel powder was prepared. FTIR spectra of pellets containing AAm-MBAAm and AAm-LiMA-MBAAm gels were given in Figure 1. FT-IR spectra of P(AAm-MBAAm) and P(AAm-LiMA-MBAAm) exhibits board peaks in the range of $3350-3450 \mathrm{~cm}^{-1}$. These peaks were assigned to the $\mathrm{N}-\mathrm{H}$ stretching of $\mathrm{NH}_{2}$ groups. The peaks appearing at $2925-2930 \mathrm{~cm}^{-1}$ indicate $\mathrm{C}-\mathrm{H}$ stretching of $-\mathrm{CH}_{3}$ and $-\mathrm{CH}_{2}-$ groups. The observed peak at $1552 \mathrm{~cm}^{-1}$ has been attributed to $-\mathrm{C}=\mathrm{O}$ stretching of $-\mathrm{COO}^{-}$ groups (Figure 1, curve 1), and the peaks observed at $1657-1660 \mathrm{~cm}^{-1}$ were assigned $-\mathrm{C}=\mathrm{O}$ stretching band of amide groups (Figure 1, curves 1 and 2) as explained in previous studies [60-62]. 


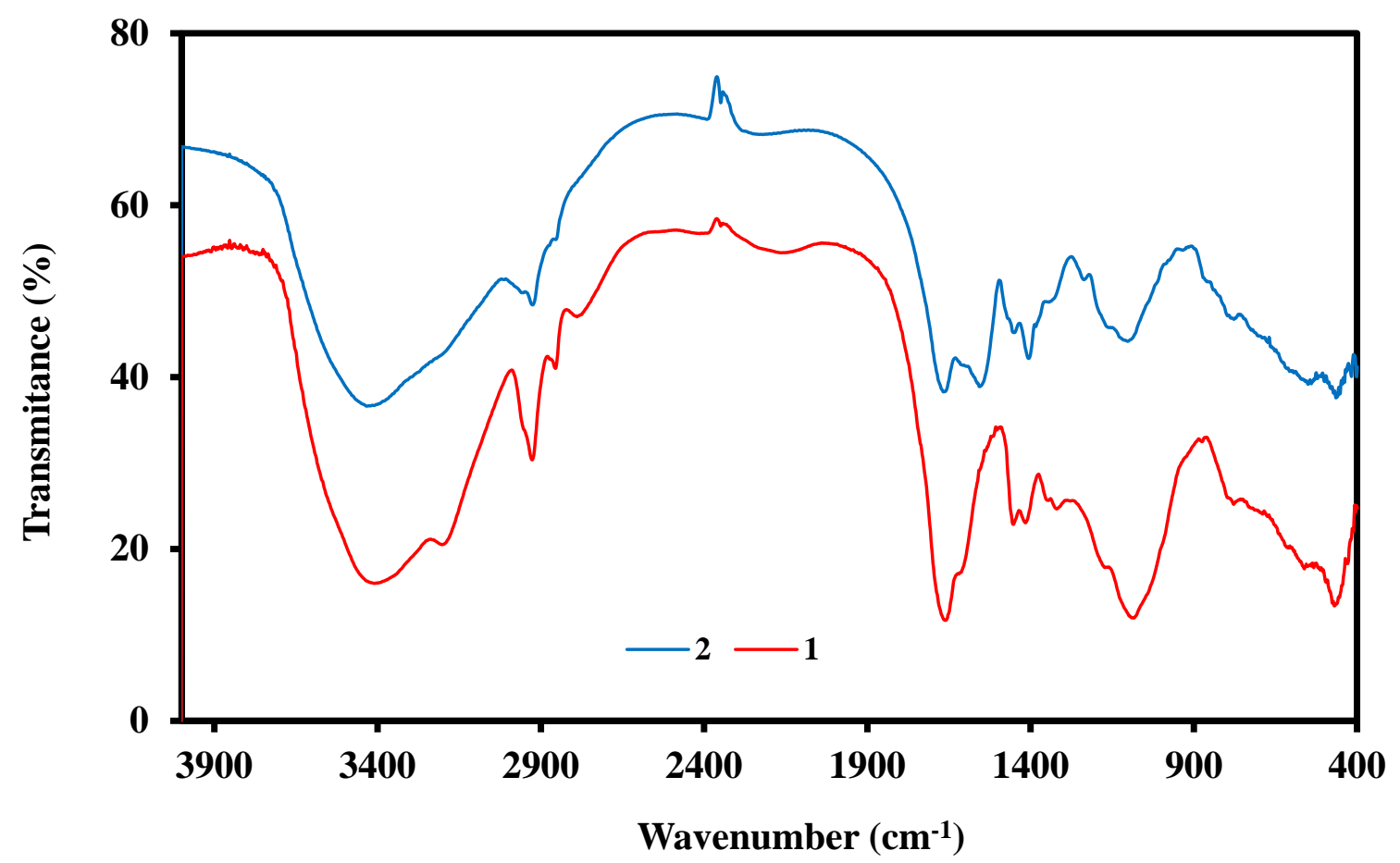

Figure 1. FTIR analyses of AAm-MBAAm (curve 1) and AAm-LiMA-MBAAm (curve 2).

2.6. $\mathrm{Cu}(\mathrm{II})$ adsorption experiments on the swollen hydrogel.

For adsorption measurements of copper ions from aqueous solutions on swollen hydrogel, the batch method was used. For this purpose, the AAm-LiMA-MBAAm hydrogel of 0.105 mol AAm, 0.070 mol LiMA and $8.75 \times 10^{-4}$ mol MBAAm was synthesized, and its equilibrium swelling ratio in distilled water was determined as $77.7 \mathrm{~g} \mathrm{H}_{2} \mathrm{O} / \mathrm{g}$ dried gel. Before starting adsorption experiments, the dried hydrogel was ground into powder and immersed in excess of distilled water for one week for hydrogel to reach an equilibrium swelling ratio. The hydrogel, which reaches to equilibrium swelling ratio, was separated from the solution. For removal measurements of copper ions from aqueous solutions, the obtained hydrogel was immersed into $10 \mathrm{~mL}$ of $\mathrm{Cu}$ (II) solution and effects of parameters such as the amount of adsorbent $(\mathrm{m}=0.02,0.03,0.05,0.10,0.15,0.20$ and $0.30 \mathrm{~g})$ at constant initial $\mathrm{Cu}(\mathrm{II})$ concentration of $0.1 \mathrm{~mol} / \mathrm{L}$, time $(\mathrm{t}=60 \mathrm{~min})$ and temperature $(\mathrm{T}=293 \mathrm{~K})$, initial $\mathrm{Cu}(\mathrm{II})$ concentration $\left(\mathrm{C}_{0}=0.04,0.06,0.10,0.20\right.$ and $\left.0.30 \mathrm{~mol} / \mathrm{L}\right)$ at constant amount of adsorbent $(\mathrm{m}=0.15 \mathrm{~g})$ and contact time $(\mathrm{t}=60 \mathrm{~min})$, adsorption time $(\mathrm{t}=2,4,6,10,15,20,40$ and $60 \mathrm{~min})$ for $\mathrm{T}=293 \mathrm{~K}, \mathrm{~m}=0.15 \mathrm{~g}$ and various $\mathrm{Cu}(\mathrm{II})$ concentrations of $0.06,0.1$ and $0.2 \mathrm{~mol} / \mathrm{L}$ and $\mathrm{pH}$ of solution ( $\mathrm{pH}=4,6$ and 7 ) at $293 \mathrm{~K}$ for $\mathrm{m}=0.5 \mathrm{~g}$ and $\mathrm{C}_{\mathrm{Cu}(\mathrm{II})}=0.1 \mathrm{~mol} / \mathrm{L}$ on $\mathrm{Cu}(\mathrm{II})$ adsorption from aqueous solutions were examined. Hydrogels were separated from the solution by decantation. $\mathrm{Cu}$ (II) concentration was calculated by determining the amount of $\mathrm{Cu}$ (II) in solution at the beginning and after the effects of definite adsorption parameters such as time, initial $\mathrm{Cu}$ (II) concentration, and solution $\mathrm{pH}$. The spectrophotometric method was used to determine $\mathrm{Cu}(\mathrm{II})$ concentration in solutions at the wavelength of $600 \mathrm{~nm}$. The adsorption percentage (\%) was calculated by equation (5) given below.

$$
\text { Ads. } \%=\frac{\mathrm{C}_{0}-\mathrm{C}_{\mathrm{e}}}{\mathrm{C}_{0}} \times 100
$$

where $\mathrm{C}_{\mathrm{o}}$ is initial $\mathrm{Cu}$ (II) concentration (mol/L), $\mathrm{C}_{\mathrm{t}}$ and $\mathrm{C}_{\mathrm{e}}$ are the $\mathrm{Cu}(\mathrm{II})$ concentrations (mol/L) in solutions at the time, $\mathrm{t}$, and at equilibrium at $60 \mathrm{~min}$, respectively. 


\section{Results and Discussion}

3.1. The effects of mole ratios of total monomer/MBAAm on the swelling behaviors and kinetics of hydrogels.

The crosslinked copolymers of AAm and MBAAm in the presence of MSA and EDTANa4 were synthesized. In crosslinking copolymerization reaction, the amount of AAm was $0.175 \mathrm{~mol}$, and the mole ratios of AAm/MBAA were taken in the range of 100-800. Figure 2 shows the investigation of hydrogel swelling behaviors produced from AAm and MBAAm at different ratios of nAAm/nMBAAm and at constant concentrations of MSA and EDTANa4 using cerium(IV) sulfate solution. As can be seen from Figure 2, the increase in the ratios of nAAm/nMBAAm from 100 to 800 resulted in an increase in the equilibrium swelling ratio from 12.97 to $26.71 \mathrm{~g} \mathrm{H} 2 \mathrm{O} / \mathrm{g}$ dried gel.

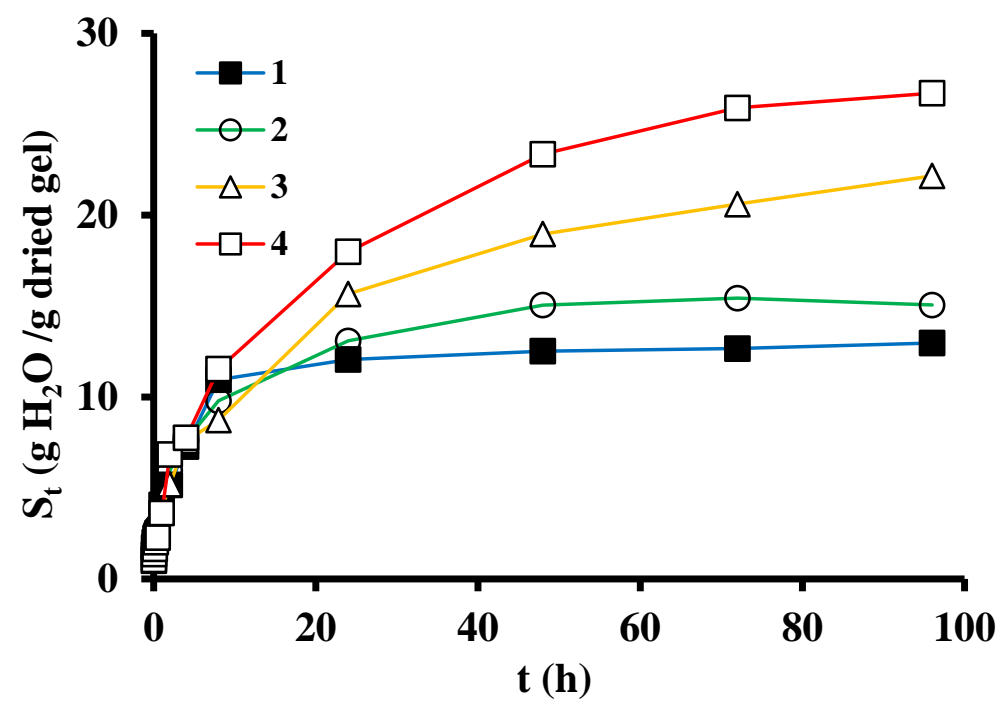

Figure 2. The swelling behaviors of hydrogels produced from AAm and MBAAm at different ratios of $\mathrm{n}_{\mathrm{AAm}} / \mathrm{n}_{\text {MBAAm }}$ and at constant concentrations of MSA and EDTANa 4 using cerium(IV) sulfate solution. $\mathrm{n}_{\text {AAm }} / \mathrm{n}_{\text {MBAAm }}=100$ (curve 1), 200 (curve 2), 400 (curve 3 ) and 800 (curve 4 ). $\mathrm{n}_{\text {AAm }}=0.175$ mol.

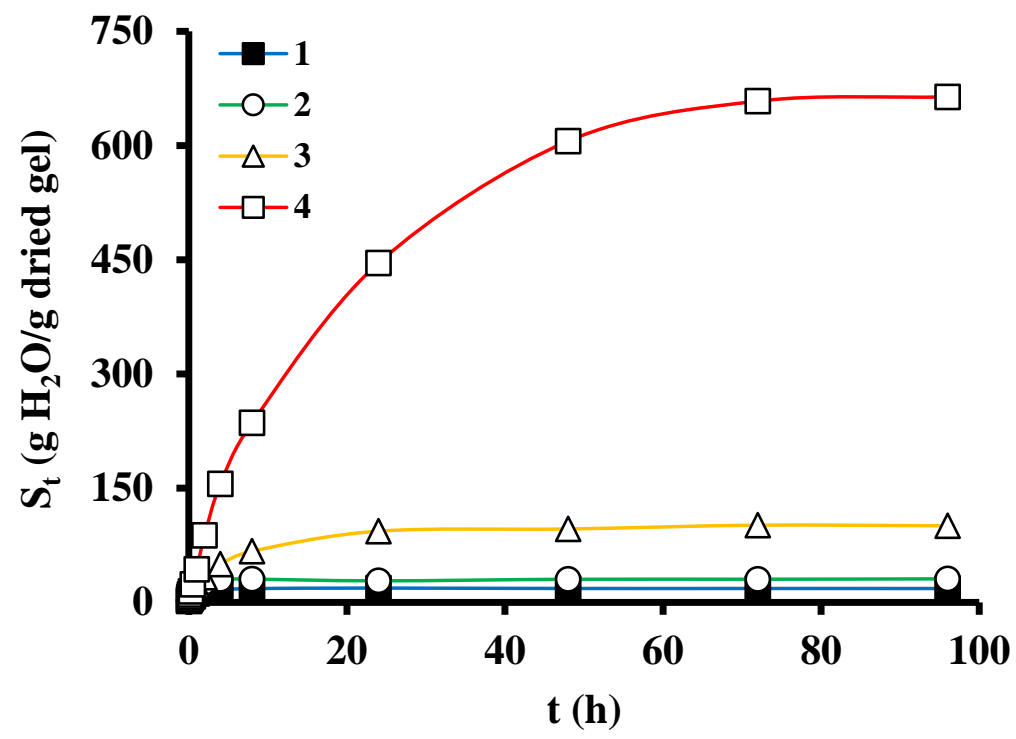

Figure 3. The relationship between swelling ratios and time for the hydrogels synthesized at constant $\mathrm{n}_{\mathrm{LiMA}}=0.035 \mathrm{~mol}$ and $\mathrm{n}_{\mathrm{AAm}}=0.140 \mathrm{~mol}$ and at various amounts of crosslinker ranging from $17.50 \times 10^{-4}$ to $21.87 \times 10^{-5}$ mol. $\mathrm{n}_{\mathrm{M}} / \mathrm{n}_{\text {MBAAm }}=100$ (curve 1), 200 (curve 2), 400 (curve 3 ) and 800 (curve 4), $\left.\mathrm{n}_{\mathrm{M}}=\mathrm{n}_{\text {LiMA }}+\mathrm{n}_{\mathrm{AAm}}=0.175 \mathrm{~mol}\right)$. 
Figure 3 shows the relationship between swelling ratios and time for the hydrogels synthesized at constant $\mathrm{n}_{\mathrm{LiMA}}=0.035 \mathrm{~mol}$ and $\mathrm{n}_{\mathrm{AAm}}=0.140 \mathrm{~mol}$ and at various amounts of crosslinker ranging from $17.50 \times 10^{-4}$ to $21.87 \times 10^{-5} \mathrm{~mol}(\mathrm{~nm} / \mathrm{nmBAAm}=100,200,400$ and 800 , $\left.\mathrm{n}_{\mathrm{M}}=\mathrm{n}_{\mathrm{LiMA}}+\mathrm{n}_{\mathrm{AAm}}=0.175 \mathrm{~mol}\right)$. As seen from Figure 3 , increasing the mole ratios of $\mathrm{nM} / \mathrm{nMBAAm}$ increased the equilibrium swelling ratio from 18.24 to $663.92 \mathrm{H}_{2} \mathrm{O} / \mathrm{g}$ dried gel.

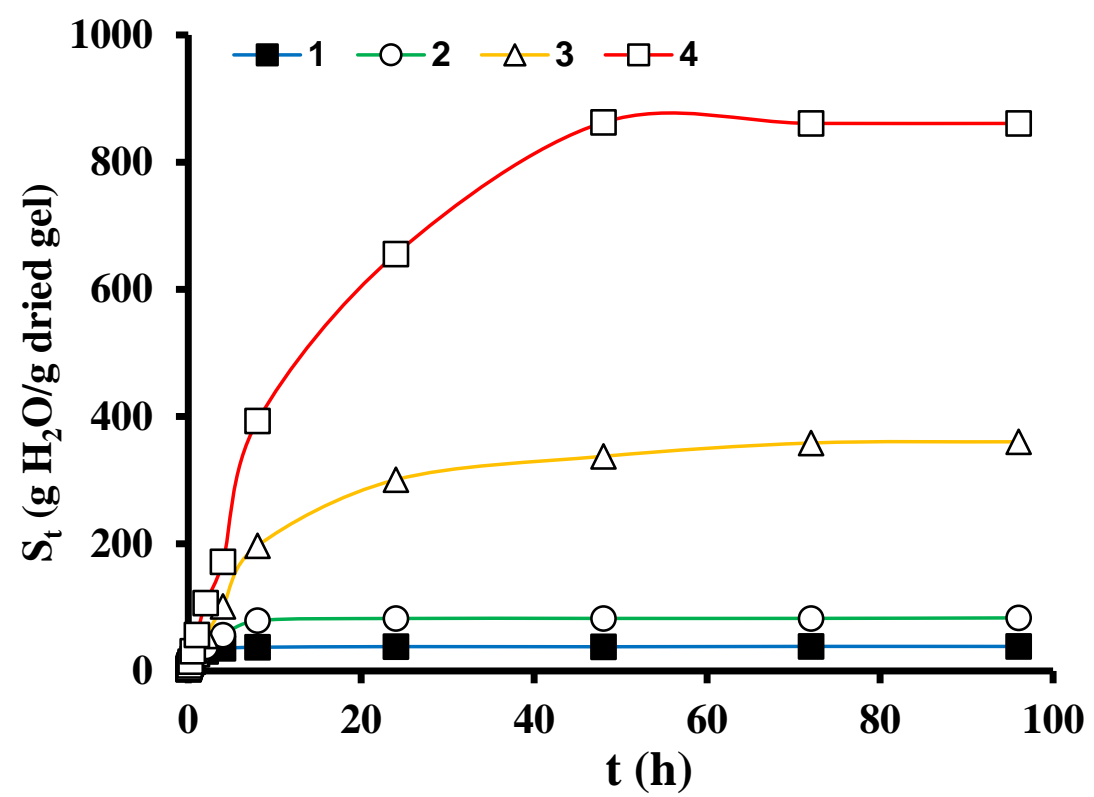

Figure 4. The dependence of swelling ratios in distilled water on time for hydrogels synthesized at constant $\mathrm{n}_{\mathrm{LiMA}}=0.105 \mathrm{~mol}$ and $\mathrm{n}_{\mathrm{AAm}}=0.070 \mathrm{~mol}$ for various amount of crosslinker. $\mathrm{n}_{\mathrm{M}} / \mathrm{n}_{\text {MBAAm }}=100$ (curve 1 ), 200 (curve 2), 400 (curve 3) and 800 (curve 4), $\mathrm{n}_{\mathrm{M}}=\mathrm{n}_{\mathrm{LiMA}}+\mathrm{n}_{\mathrm{AAm}}=0.175 \mathrm{~mol}$.

When the mole amounts of LiMA and AAm were taken as 0.105 and $0.070 \mathrm{~mol}$, respectively, in copolymerization reaction of AAm and LiMA in the presence of various molar amounts of crosslinker, the equilibrium swelling ratios of synthesized hydrogels in distilled water resulted in an increase from 36.63 to $860.90 \mathrm{H}_{2} \mathrm{O} / \mathrm{g}$ dried gel with increasing the ratios of $\mathrm{n}_{\mathrm{M}} / \mathrm{n}_{\text {MBAAm }}$ from 100 to 800 , respectively as given in Figure 4.

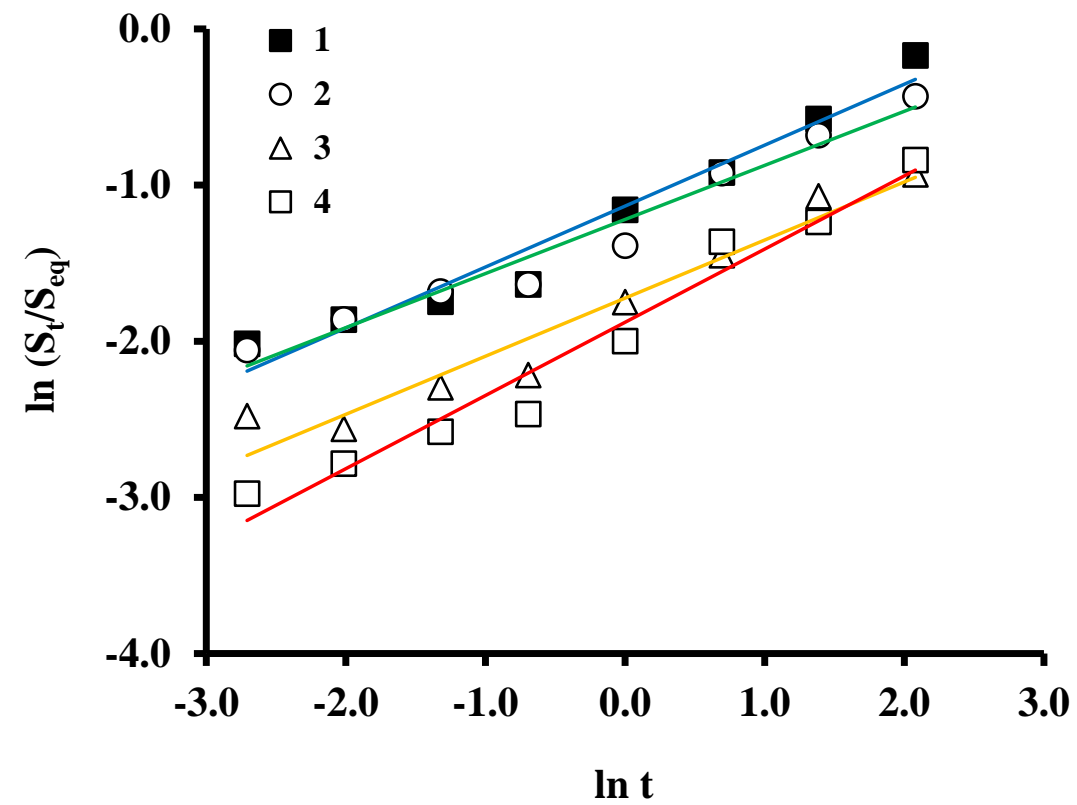

Figure 5. The effects of crosslinker concentrations on the swelling kinetics of synthesized hydrogels produced from AAm and MBAAm by using the redox initiator system of MSA and Ce(IV). $\mathrm{n}_{\mathrm{AAm}} / \mathrm{n}_{\mathrm{MBAAm}}=100$ (curve 1 ), 200 (curve 2), 400 (curve 3) and 800 (curve 4). $\mathrm{n}_{\mathrm{AAm}}=0.175 \mathrm{~mol}$. 
Consequently, the results given in Figures 2-4 indicate that hydrogels having less crosslinking degree swell more than those having more crosslinking degree. In order to describe the phenomenon of swelling of hydrogel having more crosslinked bonds, it has been assumed that phase separation occurred in the system, and it has been explained by entanglements between chains developing during polymerization in water medium as described in previous studies [40, 56-59, 63].

Table 1. The dependence of swelling kinetic parameters to monomer and crosslinker concentrations for the hydrogels synthesized from monomers of LiMA and AAm in the presence of MBAAm. $n_{M}=n_{A A m}+n_{L i M A}=0.175$

\begin{tabular}{r|r|r|r|r|r} 
& \multicolumn{6}{|c}{ mol and when $\mathrm{n}_{\text {LiMA }}=0, \mathrm{n}_{\mathrm{M}}=\mathrm{n}_{\text {AAm }}=0.175$ mol. } \\
\cline { 4 - 6 } $\mathbf{n}_{\text {AAm }}(\mathbf{m o l})$ & & & \multicolumn{2}{c}{ Swelling kinetic parameters } \\
\cline { 4 - 6 } & $\mathbf{n}_{\text {LiMA }} / \mathbf{n}_{\text {AAm }}$ & $\mathbf{n}_{\mathbf{M}} / \mathbf{n}_{\text {MBAAm }}$ & $\mathbf{n}$ & $\mathbf{k}$ & $\mathbf{R}^{\mathbf{2}}$ \\
\hline 0.175 & 0 & 100 & 0.390 & 0.322 & 0.960 \\
0.175 & 0 & 200 & 0.346 & 0.295 & 0.965 \\
0.175 & 0 & 400 & 0.372 & 0.178 & 0.947 \\
0.175 & 0 & 800 & 0.469 & 0.153 & 0.964 \\
\hline 0.140 & 0.25 & 100 & 0.481 & 0.602 & 0.996 \\
0.140 & 0.25 & 200 & 0.621 & 0.620 & 0.981 \\
0.140 & 0.25 & 400 & 0.605 & 0.215 & 0.976 \\
0.140 & 0.25 & 800 & 0.725 & 0.068 & 0.978 \\
\hline 0.070 & 1.50 & 100 & 0.486 & 0.633 & 0.986 \\
0.070 & 1.50 & 200 & 0.609 & 0.289 & 0.985 \\
0.070 & 1.50 & 400 & 0.688 & 0.078 & 0.973 \\
0.070 & 1.50 & 800 & 0.907 & 0.065 & 0.996 \\
\hline 0.140 & 0.25 & 100 & 0.481 & 0.580 & 0.996 \\
0.105 & 0.67 & 100 & 0.471 & 0.760 & 9.989 \\
0.070 & 1.50 & 100 & 0.484 & 0.565 & 0.986 \\
0.035 & 4.00 & 100 & 0.716 & 0.605 & 0.985 \\
\hline 0.140 & 0.25 & 800 & 0.725 & 0.068 & 0.978 \\
0.105 & 0.67 & 800 & 0.884 & 0.048 & 0.991 \\
0.070 & 1.50 & 800 & 0.907 & 0.065 & 0.996
\end{tabular}

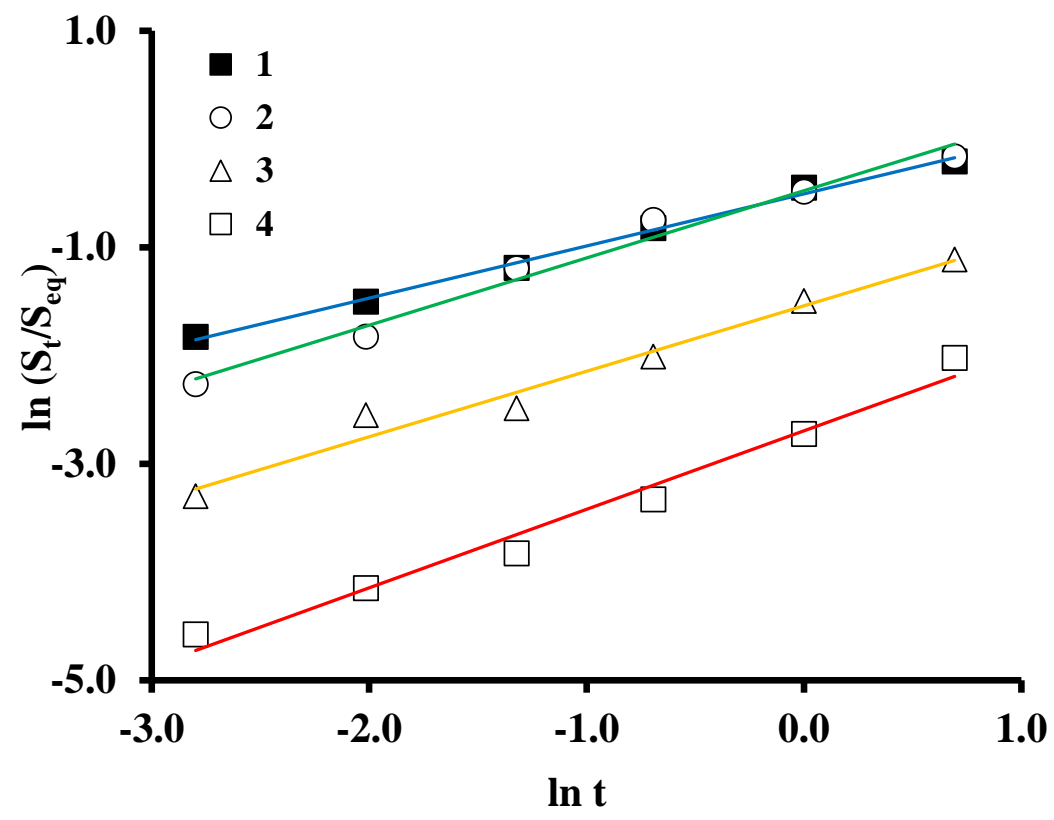

Figure 6. The dependence of swelling kinetics of hydrogels to various ratios of $n_{M} / n_{\text {MBAAm }}=100$ (curve 1), 200 (curve 2), 400 (curve 3) and 800 (curve 4), $\mathrm{n}_{\mathrm{LiMA}}=0.035, \mathrm{n}_{\mathrm{AAm}}=0.140$ and $\mathrm{n}_{\mathrm{M}}=\mathrm{n}_{\mathrm{LiMA}}+\mathrm{n}_{\mathrm{AAm}}=0.175 \mathrm{~mol}$.

To examine the effects of crosslinker concentrations on the swelling kinetics of synthesized hydrogels, Peppas kinetic relation, which is given as equation (4), was used. In 
case of that, the mole amount of AAm $=0.175 \mathrm{~mol}$ without using LiMA in the presence of various crosslinker mole amounts (nMBAAm $=17.50 \times 10^{-4}, 8.75 \times 10^{-4}, 4.375 \times 10^{-4}$ and $2.187 \times 10^{-4}$ $\mathrm{mol})$ in hydrogel synthesis reaction, the $\ln \left(\mathrm{S}_{\mathrm{t}} / \mathrm{S}_{\mathrm{eq}}\right)$ versus to $\ln \mathrm{t}$ was shown in Figure 5 . The kinetic parameters ( $\mathrm{k}$ and $\mathrm{n}$ values) determined from slope and intercept of straight lines obtained from applying swelling kinetic data to the Peppas kinetic equation for hydrogels synthesized at different mole ratios of AAm/MBAAm have been summarized in Table 1. As observed from Table 1 and Figure 5, the experimental results showed that an increasing molar ratio of $n_{A A m} / n_{M B A A m}$ from 100 to 800 increased the $n$ values ranging from 0.390 to 0.469 , whereas the $\mathrm{k}$ value decreased from 0.322 to 0.153 .

To indicate the effects of $\mathrm{n}_{\mathrm{M}} / \mathrm{n}_{\mathrm{MBAAm}}$ on the swelling kinetic parameters, the mole amounts of LiMA and AAm were taken as $0.035 \mathrm{~mol}$ and $0.140 \mathrm{~mol}$, respectively in the copolymerization reaction of AAm and LiMA for various ratios of $\mathrm{n}_{\mathrm{M}} / \mathrm{n}_{\mathrm{MBAAm}}=100,200,400$ and 800 , the $n$ values increased from 0.481 to 0.725 and $\mathrm{k}$ values decreased from 0.602 to 0.068 respectively with increasing the ratios $\mathrm{n}_{\mathrm{M}} / \mathrm{n}_{\text {MBAAm }}$ in copolymerization reaction (Figure 6 and Table 1) This indicates that swelling slope parameter (n value) was found as higher value when LiMA was added the copolymerization reaction. Moreover, it was observed that the swelling rate accelerates with adding LiMA to copolymerization reaction and with increasing the ratios of $\mathrm{n}_{\mathrm{M}} / \mathrm{n}_{\mathrm{MBAAm}}$ in copolymerization reaction.

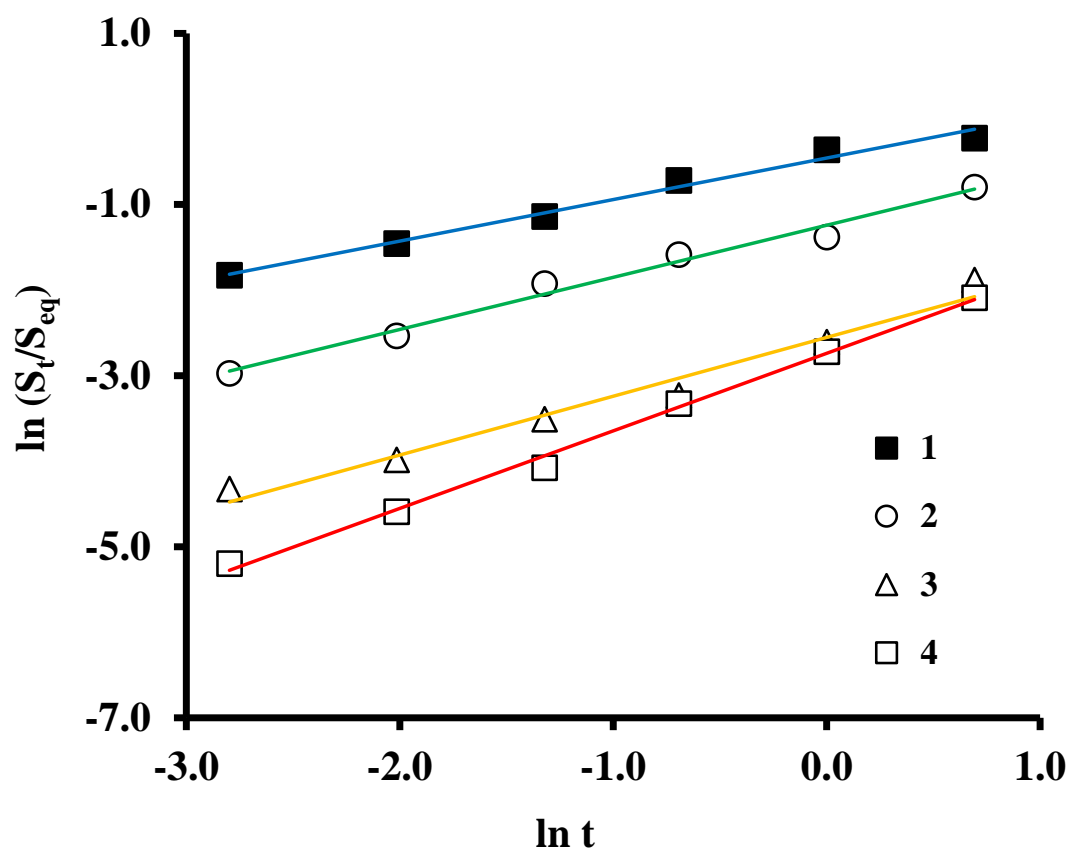

Figure 7. The relationship between swelling kinetics and crosslinker concentration for the hydrogels synthesized at constant $\mathrm{n}_{\mathrm{LiMA}}=0.105 \mathrm{~mol}$ and $\mathrm{n}_{\mathrm{AAm}}=0.070 \mathrm{~mol}$ for various amounts of crosslinker ranging from $17.50 \times 10^{-4}$ to $21.87 \times 10^{-5} \cdot \mathrm{n}_{\mathrm{M}} / \mathrm{n}_{\text {MBAAm }}=100$ (curve 1 ), 200 (curve 2), 400 (curve 3) and 800 (curve 4), $\mathrm{n}_{\mathrm{M}}=\mathrm{n}_{\text {LiMA }}+\mathrm{n}_{\mathrm{AAm}}=0.175 \mathrm{~mol}$.

When the mole amounts of LiMA and AAm were taken as $0.105 \mathrm{~mol}$, and $0.070 \mathrm{~mol}$ in hydrogel synthesis for various ratios of $\mathrm{n}_{\mathrm{M}} / \mathrm{n}_{\mathrm{MBAAm}}$ ranging from 100 to 800 , the swelling rate of LiMA-AAm-MBAAm hydrogels synthesized at different crosslinker concentrations $\left(\mathrm{n}_{\mathrm{M}} / \mathrm{n}_{\text {MBAAm }}=100,200,400\right.$ and $\left.800, \mathrm{n}_{\mathrm{M}}=\mathrm{n}_{\mathrm{LiMA}}+\mathrm{n}_{\mathrm{AAm}}=0.175 \mathrm{~mol}\right)$ was shown in Figure 7 and swelling kinetic parameters were listed in Table 1.As can be seen from Figure 7 and Table 1, the $\mathrm{n}$ value increased from 0.4860 .907 and the $\mathrm{k}$ value decreased 0.633 to 0.065 with increasing the ratios of nm/nmBAAm from 100 to 800 , respectively. 
According to the comparison of $\mathrm{n}$ values determined from Figures 6-7 and given in Table 1, it was observed that when the mole amount of LiMA increased from 0.035 to 0.105 mol in the synthesis of AAm-LiMA-MBAAm hydrogel, the calculated $n$ value at lower crosslinker amount was found as a bigger value $(n=0.907)$. This indicates that when AAmLiMA-MBAAm hydrogel was synthesized at lower crosslinker and higher LiMA concentrations, the swelling rate of synthesized hydrogels in distilled water is fast.

\subsection{The effects of ratios of $n_{L i M A} / n_{A A m}$ on swelling behaviors and kinetics of hydrogels.}

To indicate the effects of mole amounts of LiMA/AAm on the equilibrium swelling ratios, the copolymers containing various ratios of $n_{\text {LiMA }} / n_{A A m}$ ranging from 0.025 to 4 in the presence of MSA and EDTANa4 at constant mole amount of crosslinker ( $\mathrm{n}_{\mathrm{MBAAm}}=17.50 \times 10^{-4}$ mol) by using $\mathrm{Ce}(\mathrm{IV})$ dissolved in $\mathrm{H}_{2} \mathrm{SO}_{4}$ solution were synthesized. The swelling behaviors of synthesized hydrogels were examined in distilled water. It was observed that the increase in the ratios of $\mathrm{n}_{\mathrm{LiMA}} / \mathrm{n}_{\mathrm{AAm}}$ ranging from 0.25 to 4 increased to the equilibrium swelling ratios from 18.24 to $52.63 \mathrm{~g} \mathrm{H}_{2} \mathrm{O} / \mathrm{g}$ dried gel (Figure 8).

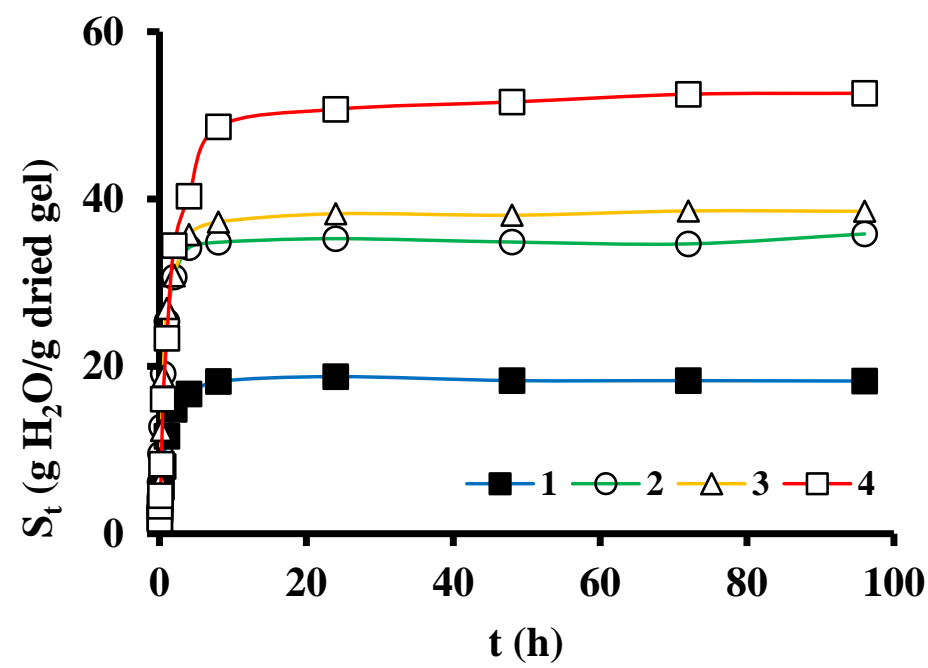

Figure 8. The effects of mole amounts of LiMA/AAm on swelling ratios for the copolymers synthesized at various ratios of $\mathrm{n}_{\mathrm{LiMA}} / \mathrm{n}_{\mathrm{AAm}}$ ranging from 0.25 to 4 in presence of MSA and EDTANa 4 at constant mole amount of crosslinker by using $\mathrm{Ce}\left(\mathrm{IV}\right.$ ) dissolved in $\mathrm{H}_{2} \mathrm{SO}_{4}$ solution. $\mathrm{n}_{\text {LiMA }} / \mathrm{n}_{\mathrm{AAm}}=0.25$ (curve 1), 0.67 (curve 2), 1.50 (curve 3 ) and 4.00 (curve 4 ). $\mathrm{n}_{\mathrm{M}}=\mathrm{n}_{\mathrm{LiMA}}+\mathrm{n}_{\mathrm{AAm}}=0.175 \mathrm{~mol}$ and $\mathrm{n}_{\text {MBAAm }}=17.50 \times 10^{-4}$ mol.

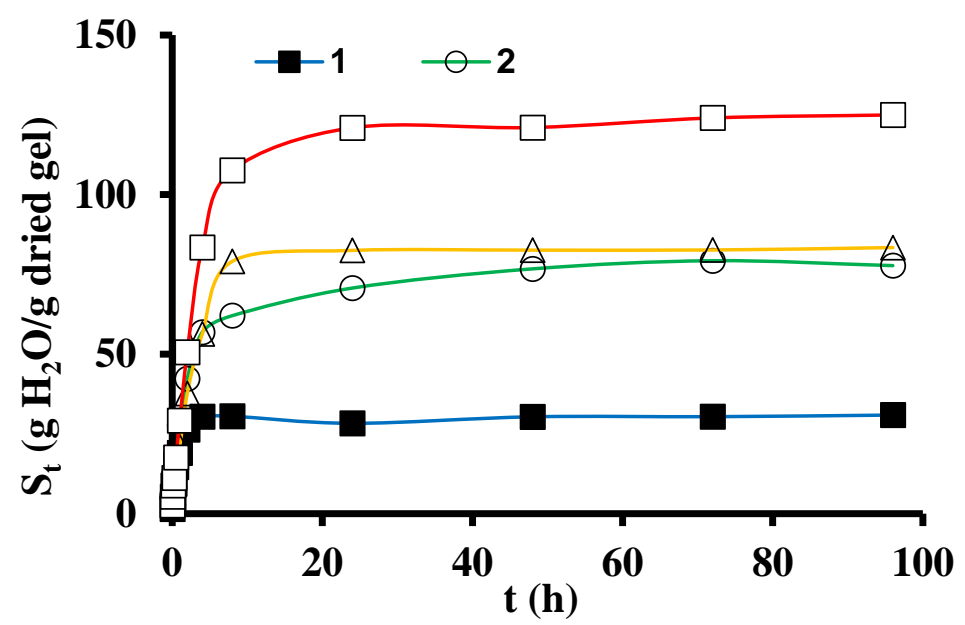

Figure 9. The relationship between swelling ratios and molar amounts of LiMA/AAm for the hydrogels synthesized at constant amount of crosslinker $\left(\mathrm{n}_{\text {MBAAm }}=8.75 \times 10^{-4} \mathrm{~mol}\right)$ at different ratios of $\mathrm{n}_{\text {LiMA }} / \mathrm{n}_{\text {AAm }}=0.25$ (curve 1 ), 0.67 (curve 2 ), 1.50 (curve 3 ) and 4.00 (curve 4 ). $\mathrm{n}_{\mathrm{M}}=\mathrm{n}_{\text {LiMA }}+\mathrm{n}_{\mathrm{AAm}}=0.175 \mathrm{~mol}$. 
When the mole amount of MBAAm was taken $8.76 \times 10^{-4}$ mol in copolymerization reaction of AAm and LiMA in the presence of MBAAm (Figure 9), the equilibrium swelling ratios of synthesized hydrogels in distilled water increased from 30.91 to $124.96 \mathrm{~g} \mathrm{H}_{2} \mathrm{O} / \mathrm{g}$ dried gel with increasing the mole ratio of LiMA/AAm from 0.25 to 4 , respectively.

In the case for hydrogels synthesized at different ratios of $\mathrm{n}_{\mathrm{LiMA}} / \mathrm{n}_{\mathrm{AAm}}$ ranging from 0.25 to 4 and at constant crosslinker concentration (nMBAAm $=4.375 \times 10^{-4} \mathrm{~mol}$ ), as shown in Figure 10, the equilibrium swelling ratios of hydrogels in distilled water increased from 100.59 to $300.66 \mathrm{H}_{2} \mathrm{O} / \mathrm{g}$ dried gel.

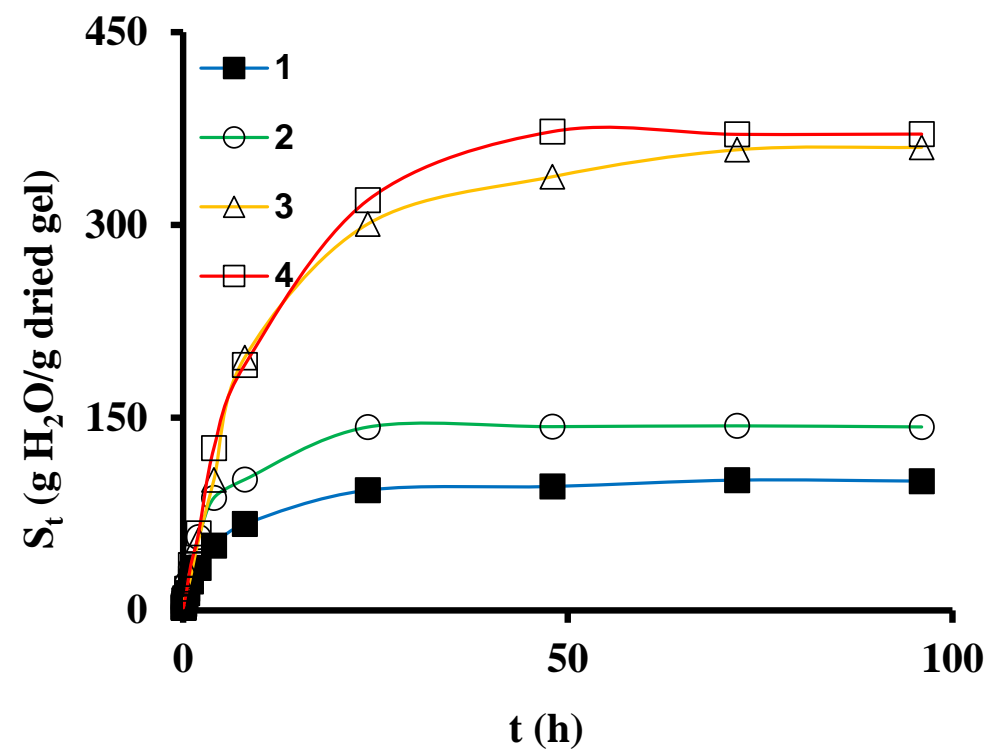

Figure 10. The dependence of swelling ratios to $n_{\text {LiMA }} / n_{A A m}=0.25$ (curve 1), 0.67 (curve 2), 1.50(curve 3) and 4.00 (curve 4 ) for the hydrogels synthesized at constant crosslinker mole amount $\left(\mathrm{n}_{\text {MBAAm }}=8.75 \times 10^{-4} \mathrm{~mol}\right)$ and at different ratios of $\mathrm{n}_{\mathrm{LiMA}} / \mathrm{n}_{\mathrm{AAm}}$ ranging from 0.25 to 4 in presence of MSA and EDTANa 4 by using Ce(IV) dissolved in $\mathrm{H}_{2} \mathrm{SO}_{4}$ solution. $\mathrm{n}_{\mathrm{M}}=\mathrm{n}_{\mathrm{LiMA}}+\mathrm{n}_{\mathrm{AAm}}=0.175 \mathrm{~mol}$.

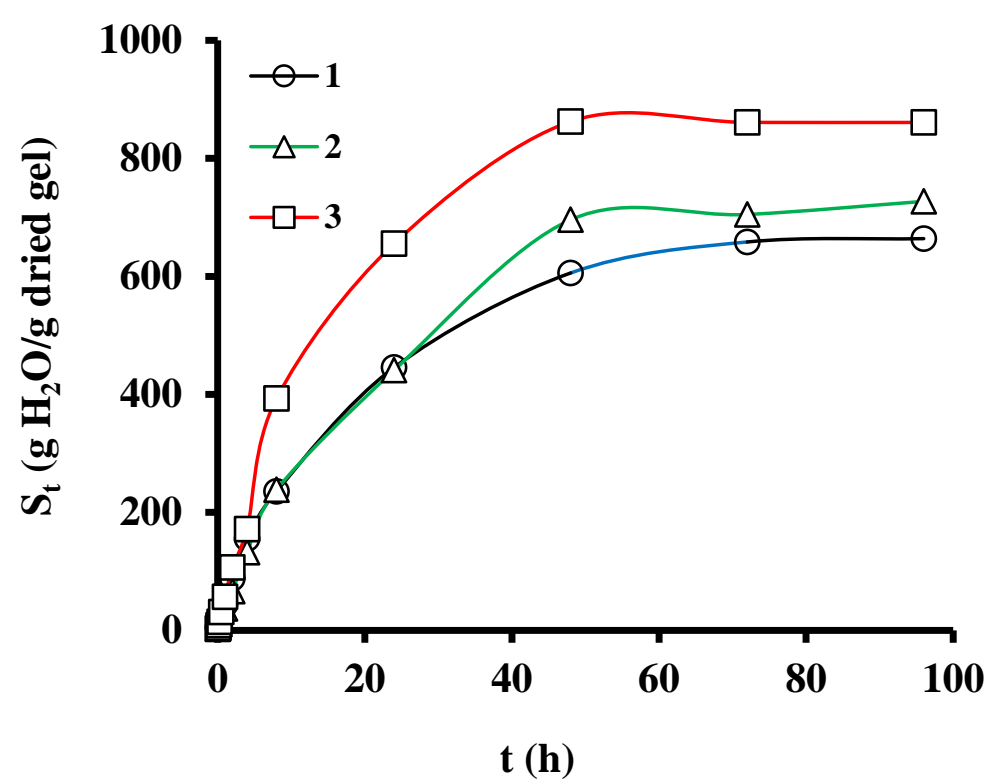

Figure 11. The effect of swelling time on the swelling ratios for hydrogels synthesized at various $n_{\text {LiMA }} / n_{\text {AAm }}$ ratios in the range from 0.25 to 1.5 and at constant amount of $\mathrm{n}_{\text {MBAAm }}=2.188 \times 10^{-2}$ mol. $\mathrm{n}_{\mathrm{M}}=\mathrm{n}_{\mathrm{LiMA}}+\mathrm{n}_{\mathrm{AAm}}=0.175$ mol. The ratios to $\mathrm{n}_{\mathrm{LiMA}} / \mathrm{n}_{\mathrm{AAm}}=0.25$ (curve 1 ), 0.67 (curve 2 ) and 1.50 (curve 3 ).

Figure 11 shows the dependence of swelling ratios to swelling time for hydrogels synthesized various $\mathrm{n}_{\mathrm{LiMA}} / \mathrm{n}_{\mathrm{AAm}}$ ratios in the range from 0.25 to 1.5 and a constant amount of nMBAAm $=2.188 \times 10^{-2} \mathrm{~mol}$. As shown in Figure 11, the equilibrium swelling ratios increased from 
663.93 to $860.90 \mathrm{H} 2 \mathrm{O} / \mathrm{g}$ dried gel, increasing the ratios of nLiMA/nAAm ranging from 0.25 to 1.5 . As can be seen from the results given in Figures 8-11, with increasing mole amount of LiMA (i.e., increasing ionized carboxyl groups), swelling and equilibrium swelling ratios increased due to the augmentation of ionic osmotic pressure or electrostatic repulsion between negatively charged carboxylate groups [40].

To analyze the dependence swelling kinetic parameters to ratios of $\mathrm{n}_{\mathrm{LiMA}} / \mathrm{n}_{\mathrm{AAm}}$ for the synthesized hydrogels of AAm ( $\mathrm{n}_{\mathrm{AAm}}=0.140,0.105,0.070$ and $0.035 \mathrm{~mol}$ ), LiMA $\left(\mathrm{n}_{\text {LiMA }}=0.035,0.070,0.105\right.$ and $\left.0.140 \mathrm{~mol}\right)$ and MBAAm $\left(\mathrm{n}_{\text {MBAAm }}=17.50 \times 10^{-4} \mathrm{~mol}\right)$ by using $\mathrm{Ce}(\mathrm{IV})$ oxidant solution prepared in $\mathrm{H}_{2} \mathrm{SO}_{4}$ solution. The natural logarithmic drawing of $\mathrm{ln}$ $\left(\mathrm{S}_{\mathrm{t}} / \mathrm{S}_{\mathrm{eq}}\right)$ against $\ln \mathrm{t}$ as illustrated in Figure 12 . The $\mathrm{k}$ and $\mathrm{n}$ values as kinetic parameters were determined from slope and intercept of straight lines for hydrogels synthesized at different mole ratios of LiMA/AAm was listed in Table 1. As observed from Table 1 and Figure 12, the experimental results showed that an increasing the ratios of $n_{\text {LiMA }} / n_{\text {AAm }}$ ranging from 0.25 to 4 increased the $\mathrm{n}$ values ranging from 0.481 to 0.716 , whereas the $\mathrm{k}$ value was observed in the range of $0.580-760$.

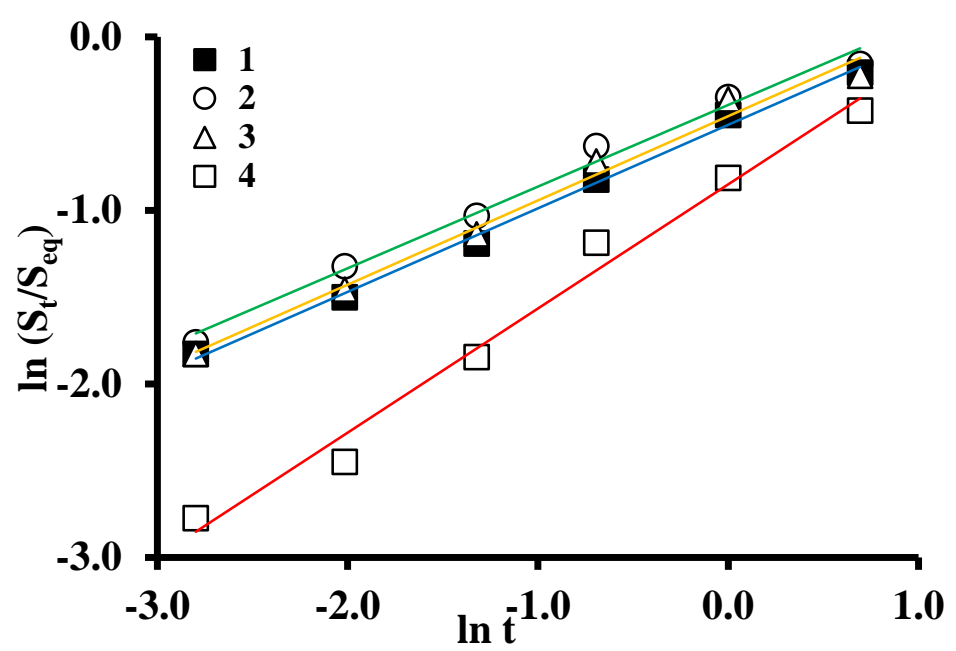

Figure 12. The dependence of swelling kinetic parameters to ratios of $\mathrm{n}_{\mathrm{LiMA}} / \mathrm{n}_{\mathrm{AAm}}$ for the synthesized hydrogels of AAm ( $\mathrm{n}_{\mathrm{AAm}}=0.140,0.105,0.070$ and $\left.0.035 \mathrm{~mol}\right)$, LiMA ( $\mathrm{n}_{\text {LiMA }}=0.035,0.070,0.105$ and $\left.0.140 \mathrm{~mol}\right)$ and

MBAAm ( $\left.\mathrm{n}_{\text {MBAAm }}=17.50 \times 10^{-4} \mathrm{~mol}\right)$ by using $\mathrm{Ce}(\mathrm{IV})$ oxidant solution prepared in $\mathrm{H}_{2} \mathrm{SO}_{4}$ solution. $\mathrm{n}_{\text {LiMA }} / \mathrm{n}_{\text {AAm }}=0.25$ (curve 1 ), 0.67 (curve 2), 1.50 (curve 3 ) and 4.00 (curve 4 ). $\mathrm{n}_{\mathrm{M}}=\mathrm{n}_{\text {LiMA }}+\mathrm{n}_{\mathrm{AAm}}=0.175 \mathrm{~mol}$.

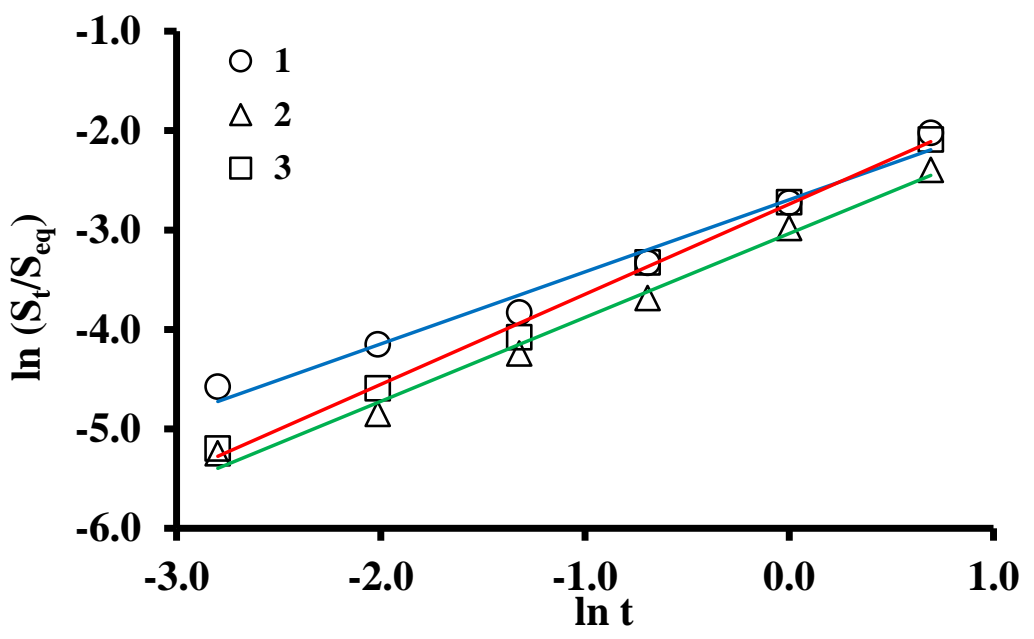

Figure 13. The effect of ratios of $\mathrm{n}_{\mathrm{LiMA}} / \mathrm{n}_{\mathrm{AAm}}$ on swelling kinetics for the hydrogels synthesized at constant amount of crosslinker $\left(n_{\text {MBAAm }}=2.188 \times 10^{-4} \mathrm{~mol}\right)$ at different ratios of $n_{\text {LiMA }} / n_{\text {AAm }}=0.25$ (curve 1), 0.67 (curve 2) and $1.50($ curve 3$) . \mathrm{n}_{\mathrm{M}}=\mathrm{n}_{\text {LiMA }}+\mathrm{n}_{\mathrm{AAm}}=0.175 \mathrm{~mol}$. 
When the amount of nMBAAm was taken $2.188 \times 10^{-4} \mathrm{~mol}$ in the copolymerization reaction of AAm and LiMA for various ratios of $\mathrm{nm} / \mathrm{nMBAAm}_{\mathrm{n}}=0.25,0.67$ and 1.50 , the $\mathrm{n}$ values increased from 0.725 to 0.907 , and $\mathrm{k}$ values were determined in the range of $0.048-0.068$ with increasing the ratios $n_{L i M A} / n_{A A m}$ in copolymerization reaction (Figure 13 and Table 1). This indicates that the $n$ value, the swelling slope parameter, increased with increasing the ratios $n_{L i M A} / n_{A A m}$ in copolymerization reaction and decreasing crosslinker mole amount. Consequently, the swelling rate accelerates with an increasing mole ratio of LiMA/AAm at low crosslinker concentration in copolymerization reaction $[40,63]$.

\subsection{The $\mathrm{Cu}(I I)$ removal studies from aqueous solutions on AAm-LiMA-MBAAm hydrogel.}

To study the effect of the amount of hydrogel on $\mathrm{Cu}$ (II) adsorption from aqueous solution, various amounts of dried gel containing LiMA groups were swollen in access of water for one week, and each of the obtained swollen gels was mixed with $10 \mathrm{~mL}$ of $\mathrm{Cu}$ (II) solution $(0.1 \mathrm{~mol} / \mathrm{L})$ at $293 \mathrm{~K}$ and at constant adsorption time ( $\mathrm{t}=60 \mathrm{~min})$. After adsorption time was completed, cupper ions were determined in solution by spectrometric measurements, and the amount of adsorbed $\mathrm{Cu}$ (II) into swollen gel was calculated.

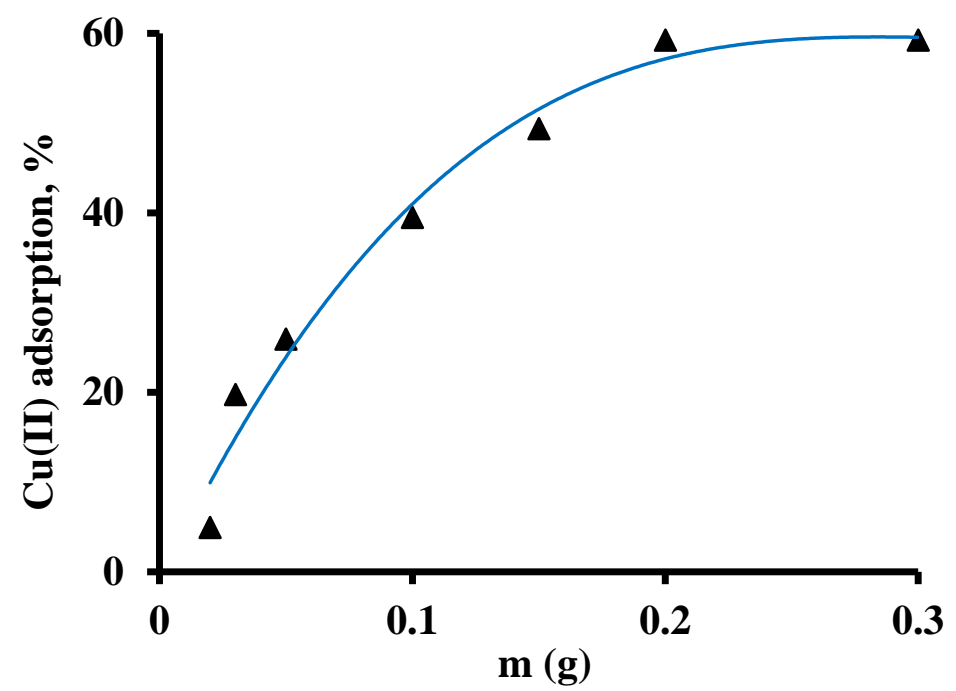

Figure 14. The relation between the amount of dried gel and $\mathrm{Cu}(\mathrm{II})$ adsorption percentage into the swollen gel. $\mathrm{C}_{\mathrm{Cu}(\mathrm{II})}=0.1 \mathrm{~mol}, \mathrm{~T}=293 \mathrm{~K}$ and $\mathrm{t}=60 \mathrm{~min}$.

Figure 14 shows the relation between the amount of dried gel and $\mathrm{Cu}(\mathrm{II})$ adsorption percentage into the swollen gel. As can be seen from Figure 14, with increasing the amount of adsorbent, the adsorption percentage increased and reached an equilibrium in the range of $\mathrm{m}_{\text {adsorbent }}=0.15-0.30 \mathrm{~g}$ dried gel. Therefore, $0.15 \mathrm{~g}$ adsorbent, which has an adsorption efficiency of $48.30 \%$, was used for further adsorption measurements to investigate the effects of initial $\mathrm{Cu}$ (II) concentration, adsorption time, and $\mathrm{pH}$ of solution on hydrogel containing LiMA groups.

Dependence of $\mathrm{Cu}$ (II) adsorption percentage to initial $\mathrm{Cu}$ (II) concentration by using swollen gel bearing LiMA functional groups was investigated at a constant time of $60 \mathrm{~min}$ and at the constant adsorbent amount $(\mathrm{m}=0.15 \mathrm{~g}$ dried gel) (Figure 15). As observed from Figure 15 , the adsorption percentage of copper ions on the swollen hydrogel increased and reached a maximum value at around $\mathrm{C}_{0}=0.2 \mathrm{~mol} / \mathrm{L}$ and then slightly decreased, increasing the initial $\mathrm{Cu}$ (II) concentration. 


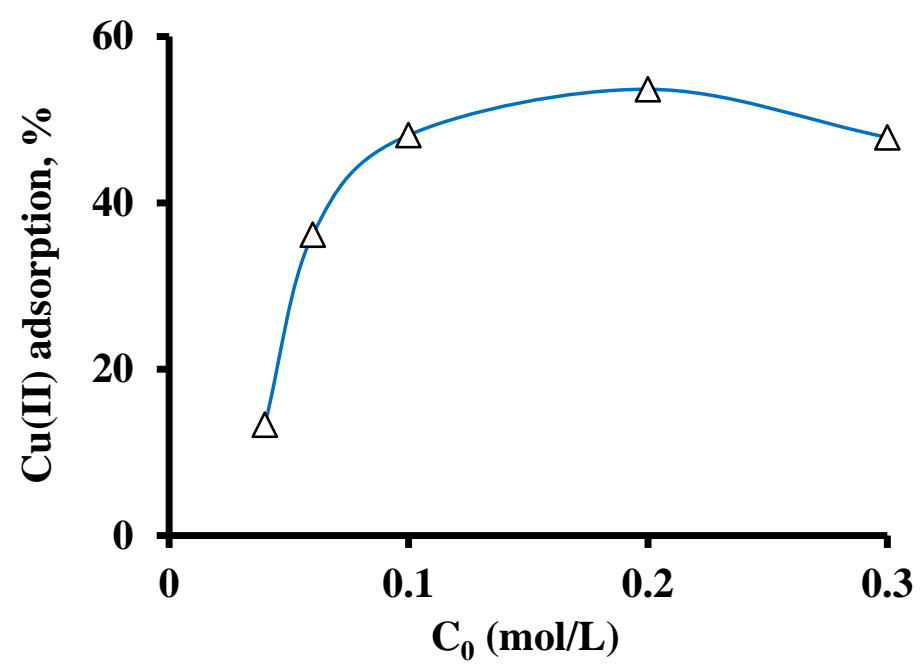

Figure 15. The dependence $\mathrm{Cu}$ (II) adsorption percentage to initial $\mathrm{Cu}$ (II) concentration ranging from 0.04 $\mathrm{mol} / \mathrm{L}$ to $0.3 \mathrm{~mol} / \mathrm{L}$ for the adsorption of $\mathrm{Cu}(\mathrm{II})$ on the swollen hydrogel. $\mathrm{m}=0.15 \mathrm{~g}$ dried gel, $\mathrm{t}=60 \mathrm{~min}, \mathrm{~T}=293$

$\mathrm{K}$.

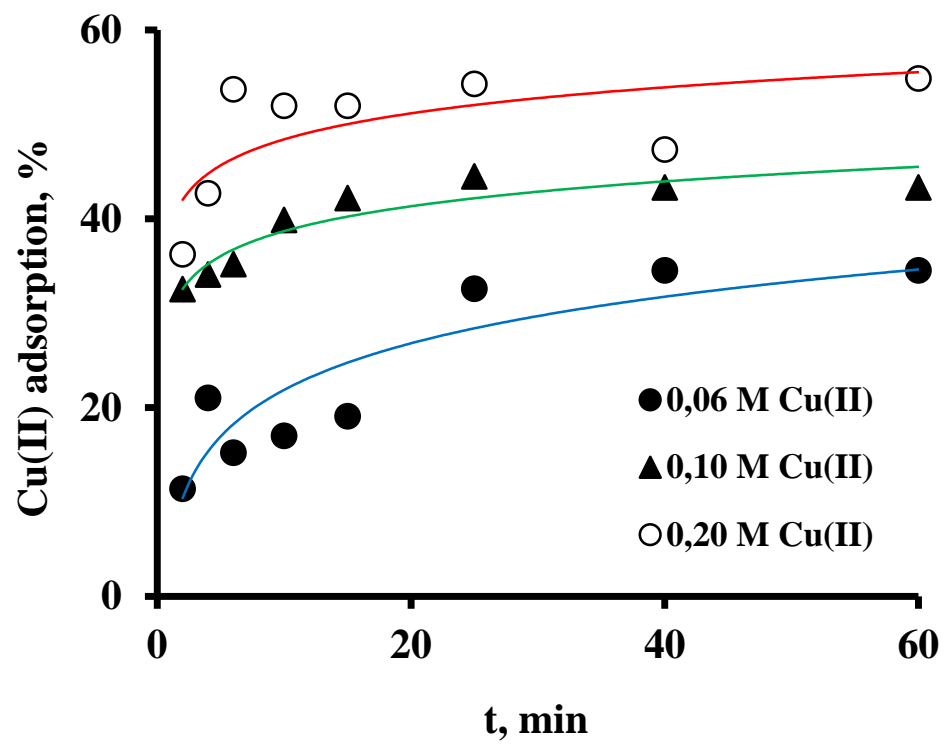

Figure 16. The effect of contact time on adsorption percentage for the $\mathrm{Cu}(\mathrm{II})$ adsorption from aqueous solution on swollen hydrogel bearing LiMA groups for various initial $\mathrm{Cu}(\mathrm{II})$ concentrations of $0.06,0.1$, and $0.2 \mathrm{~mol} / \mathrm{L}$ at $293 \mathrm{~K}$. The dried gel amount is $0.15 \mathrm{~g}$.

The effect of contact time on adsorption percentage was illustrated in Figure 16 for the $\mathrm{Cu}$ (II) adsorption from aqueous solution on swollen hydrogel bearing LiMA groups at various initial $\mathrm{Cu}$ (II) concentrations of 0.06, 0.1, and $0.2 \mathrm{~mol} / \mathrm{L}$ at $293 \mathrm{~K}$. As seen from Figure 16, with increasing contact time, the percentages of adsorbed $\mathrm{Cu}$ (II) on the swollen hydrogels bearing LiMA groups increased and reached equilibrium values in the range of $t=15-20 \mathrm{~min}$ of adsorption time. This indicates that a rapid initial $\mathrm{Cu}(\mathrm{II})$ adsorption on the swollen hydrogel has been followed by a steady and at a later stage, adsorption reached an apparent plateau in the range of 20-60 min as explained in previous studies [64,65].

Table 2. The effects of $\mathrm{pH}$ of the solution ( $\mathrm{pH}=4,6$ and 7$)$ and contact time ( $\mathrm{t}=2,3,6,10,15,25$, and 40 min) on the adsorbed $\mathrm{Cu}(\mathrm{II})$ percentage at $293 \mathrm{~K}$. The weight of dried hydrogel is $0.15 \mathrm{~g}, \mathrm{Cu}(\mathrm{II})=0.1 \mathrm{~mol} / \mathrm{L}$.

\begin{tabular}{c|c|c|c}
\multirow{2}{*}{ Adsorption time (min) } & \multicolumn{3}{|c}{$\mathbf{C u}(\mathbf{I I})$ adsorption, \% } \\
\cline { 2 - 4 } & $\mathbf{p H = 4}$ & $\mathbf{p H = 6}$ & $\mathbf{p H = 7}$ \\
\hline 2 & 33.33 & 47.22 & 33.46 \\
3 & 34.57 & 47.82 & 49.62 \\
6 & 35.80 & 58.89 & 57.31
\end{tabular}




\begin{tabular}{c|c|c|c}
\multirow{2}{*}{ Adsorption time (min) } & \multicolumn{3}{|c}{ Cu(II) adsorption, \% } \\
\cline { 2 - 4 } & $\mathbf{p H = 4}$ & $\mathbf{p H = 6}$ & $\mathbf{p H = 7}$ \\
\hline 10 & 40.74 & 56.13 & 71.15 \\
15 & 43.21 & 61.66 & 62.69 \\
25 & 45.68 & 66.80 & 72.31 \\
40 & 44.45 & 58.89 & 67.31
\end{tabular}

If adsorbents have available groups functionalized with amideoximes and phosphoric, methacrylic, acrylic, succinic, glutamic, iminoacetic and hydroxamic acids, the $\mathrm{pH}$ of the medium has a more influence upon the adsorption of toxic or radioactive metal ions on adsorbents from aqueous or waste solutions [43-44, 64-65]. In order to examine the dependence of $\mathrm{Cu}$ (II) adsorption to hydrogel bearing LiMA groups, $10 \mathrm{~mL}$ of $0.1 \mathrm{M} \mathrm{Cu}$ (II) solution at various $\mathrm{pH}=4,6$ and 7 and $0.15 \mathrm{~g}$ died gel in equilibrium swelling situation at $293 \mathrm{~K}$ were mixed at adsorption time of $60 \mathrm{~min}$. The results given in Table 2 indicate that the adsorbed $\mathrm{Cu}$ (II) amount on hydrogel increased with increasing adsorption time and $\mathrm{pH}$ of the solution. This indicates that the higher $\mathrm{Cu}(\mathrm{II})$ adsorption occurs at the value of $\mathrm{pH}=7$.

\section{Conclusions}

Homopolymeric and copolymeric hydrogels of AAm-MBAAm and AAm-LiMAMBAAm, respectively, in the presence of EDTA tetrasodium salt, were synthesized by using redox couple of $\mathrm{Ce}(\mathrm{IV})$ as oxidant and MSA as reducing agent. The dependences of swelling behaviors and kinetics of synthesized hydrogels in distilled water to the mole ratios of LiMA/AAm at constant crosslinker amount and the mole ratios of total monomer/MBAAm at constant mole amounts of LiMA and AAm were investigated. It was observed that hydrogels having less crosslinking degree swell more than hydrogels having a more crosslinking degree and with increasing the mole amount of LiMA, swelling and equilibrium swelling ratios increased due to augmentation of ionic osmotic pressure or electrostatic repulsion between negatively charged carboxylate groups in polymer chains. Furthermore, when hydrogels were synthesized at lower crosslinker and higher LiMA concentrations, the slope parameter (n value) in Peppas kinetic equation was found as the biggest value. This indicates that the swelling rate of synthesized hydrogel in distilled water accelerates at this condition.

The hydrogel with $77.7 \mathrm{~g} \mathrm{H}_{2} \mathrm{O} / \mathrm{g}$ dried gel of equilibrium swelling ratio was used to remove $\mathrm{Cu}$ (II) from an aqueous solution. The effects of adsorption parameters such as the amount of dried gel, initial $\mathrm{Cu}$ (II) concentration, adsorption time, and $\mathrm{pH}$ of solution were investigated. With increasing the amount of adsorbent, the adsorbed $\mathrm{Cu}$ (II) percentage increased and reached an equilibrium with adsorption efficiency of $48.30 \%$ in the range of 0.15-30 g of adsorbent amount. The increase in initial $\mathrm{Cu}(\mathrm{II})$ concentration increased to adsorbed $\mathrm{Cu}(\mathrm{II})$ amount. Maximum adsorption efficiency has been obtained at $\mathrm{C}_{0}=0.2 \mathrm{~mol} / \mathrm{L}$ of initial $\mathrm{Cu}$ (II) concentration. With increasing contact time, the adsorbed $\mathrm{Cu}$ (II) percentage increased rapidly at an initial time and has been followed by a steady and then reached a plateau in the range of 20-60 min of adsorption time. When the effect of solution $\mathrm{pH}$ for the $\mathrm{Cu}$ (II) adsorption on the swollen gel was examined, the higher $\mathrm{Cu}(\mathrm{II})$ adsorption was observed at the value of $\mathrm{pH}=7$.

\section{Funding}

This study was funded by the Scientific Research Projects Coordination Unit of Istanbul University-Cerrahpasa. Project number: 19504. 


\section{Acknowledgments}

The authors wish to thank the support of the Scientific Research Projects Coordination Unit of Istanbul University-Cerrahpasa.

\section{Conflicts of Interest}

The authors declare no conflict of interest.

\section{References}

1. Das, M.; Giri, T.K.; Hydrogels based on gellan gum in cell delivery and drug delivery. Journal of Drug Delivery Science and Technology 2020, 56, 101586, https://doi.org/10.1016/j.jddst.2020.101586.

2. Lim, S.U.; Ooi, C.W.; Low, E.L.; Tan, W.S.; Chan, E.S.; Ho, K.L.; Tey, B.T. Synthesis of poly(acrylamide)based hydrogel for bio-sensing of hepatitis B core antigen. Materials Chemistry and Physics 2020, 243, 122578, https://doi.org/10.1016/j.matchemphys.2019.122578.

3. Ai, F.J.; Yin, X.Z.; Hu, R.C.; Ma, H.L.; Liu, W. Research into the super-absorbent polymers on agricultural water. Agricultural Water Management 2021, 245, 106513, https://doi.org/10.1016/j.agwat.2020.106513.

4. Yu, Y.; Yang, Z.Y.; Ren, S.J.; Gao, Y.N.; Zheng, Z.Q. Multifunctional hydrogel based on ionic liquid with antibacterial performance. Journal of Molecular Liquids 2020, 299, 112185, https://doi.org/10.1016/j.molliq.2019.112185.

5. Crispim, E.G.; Piai, J.F.; Fajardo, A.R.; Ramos, E.R.F.; Nakamura, T.U.; Nakamura, C.V.; Rubira, A.F.; Muniz, E.C. Hydrogels based on chemically modified poly(vinyl alcohol) (PVA-GMA) and PVAGMA/chondroitin sulfate: Preparation and characterization. Express Polymer Letters 2012, 6, 383-395, https://doi.org/10.3144/expresspolymlett.2012.41.

6. Yao, G.H.; Bi, W.D.; Liu, H. pH-responsive magnetic graphene oxide/poly(NVI-co-AA) hydrogel as an easily recyclable adsorbent for cationic and anionic dyes. Colloids and Surfaces A 2020, 588, 124393, https://doi.org/10.1016/j.colsurfa.2019.124393.

7. Chen, Y.; Hao, Y.C.; Luo, Z.G.; Gao, Q.Y. Preparation of hydroxybutyl starch with a high degree of substitution and its application in temperature-sensitive hydrogels. Food Chemistry 2021, 355, 129472, https://doi.org/10.1016/j.foodchem.2021.129472.

8. Philippova, O.E.; Hourdet, D.; Audebert, R.; Khokhlov, A.R. pH-response gels of hidrophobically modified poly(acrylic acid). Macromolecules 1997, 30, 8278-8285, https://doi.org/10.1021/ma970957v.

9. Kataoka, K.; Miyazaki, H.; Bunya, M.; Okano, T.; Sakurai, Y. Totally synthetic polymer gels responding to external glucose concentration: Their preparation and application to on-off regulation of insulin release. Journal of the American Chemical Society 1998, 120, 12694-12695, https://doi.org/10.1021/ja982975d.

10. Miyata, T.; Asami, N.; Uragami, T. Preparation of an antigen-sensitive hydrogel using antigen-antibody bindings. Macromolecules 1999, 32, 2082-2084. https://doi.org/10.1021/ma981659g.

11. Yıldız, B.; Işık, B.; Kış M. Synthesis and characterization of thermoresponsive isopropylacrylamideacrylamide hydrogels. European Polymer Journal 2002, 38, 1343-1347, https://doi.org/10.1016/S00143057(01)00308-1.

12. Perez, J.P.H.; Lopez-Ruiz, B.; Lopez-Cabarcos, E. Synthesis, characterization of microparticles based on poly-methacrylic acid with glucose oxidase for biosensor applications. Talanta 2016, 149, 310-318, https://doi.org/10.1016/j.talanta.2015.11.053.

13. Singh, B.; Chauhan, G.S.; Kumar, S.; Chauhan, N. Synthesis, characterization and swelling responses of pH sensitive psyllium and polyacrylamide based hydrogels for the use in drug delivery (I). Carbohydrate Polymer 2007, 67, 190-200, https://doi.org/10.1016/j.carbpol.2006.05.006.

14. Dursch, T.J.; Taylor, N.O.; Liu, D.E.; Wu, R.; Prausnitz, J.M.; Radke, C.J. Water-soluble drug partitioning and adsorption in HEMA/MAA hydrogel. Biomaterials 2014, 35, 620-629, https://doi.org/10.1016/j.biomaterials.2013.09.109.

15. Zhao, C.H.; Hu, L.L.; Zhang, C.G.; Wang, S.S.; Wang, X.Z.; Huo, Z.Y. Preparation of biocharinterpenetrated iron-alginate hydrogel as a $\mathrm{pH}$-independent sorbent for removal of $\mathrm{Cr}(\mathrm{VI})$ and $\mathrm{Pb}(\mathrm{II})$. Environmental Pollution 2021, 287, 117303, https://doi.org/10.1016/j.envpol.2021.117303. 
16. Dragan, E.S.; Cocarta, A.I.; Gierszewska, M. Designing novel macroporous composite hydrogels based on methacrylic acid copolymers and chitosan and in vitro assessment of lysozyme controlled delivery. Colloid and Surfaces B: Biointerfaces 2016, 139, 33-41, https://doi.org/10.1016/j.colsurfb.2015.12.011.

17. Bajpai, M.; Bajpai, S.K.; Jyotish; P. Water absorption and moisture permeation properties of chitosan/poly(acrylamide-co-itaconic acid) IPC films. International Journal of Biological Macromolecules 2016, 84, 1-9, https://doi.org/10.1016/j.ijbiomac.2015.11.088.

18. Fan, X.C.; Yang, L.; Wang, T.; Sun, T.D.; Lu, S.T. pH-responsive cellulose-based dual drug-loaded hydrogel for wound dressing. European Polymer Journal 2019, $121, \quad 109290$, https://doi.org/10.1016/j.eurpolymj.2019.109290.

19. Shi, K.; Yang X.; Xu, J.D.; Sha, D.; Wang B.L.; Liu, X.; Liu, Z.; Ji, X.L. Preparation of polyvinyl alcohol formaldehyde- $g$-poly(2-(dimethylamino)ethyl methacrylate) macroporous hydrogels and their dual thermo/pH-responsive behavior and antibacterial performance. Reactive and Functional Polymers 2021, 164, 104916, https://doi.org/10.1016/j.reactfunctpolym.2021.104916.

20. Yang, X.; Lee, H.Y.; You, S.G.; Kim, J.C. pH- and temperature-dependent release from cationic vesicle coexisting with copolymer of $\mathrm{N}$-isopropylacrylamide and methacrylic acid. Colloid and Surface A: $\begin{array}{lllll}\text { Physicochemical and } \quad \text { Engineering } & \text { Aspects } & \text { 2009, } & 348, & \text { 109-115, }\end{array}$ https://doi.org/10.1016/j.colsurfa.2009.07.001.

21. Parvathy, P.C.; Jyothi, A.N. Synthesis, characterization and swelling behavior of superabsorbent polymers from cassava starch-graft-poly(acrylamide). Starch $\quad \mathbf{2 0 1 2}, \quad 64, \quad$ 207-218, https://doi.org/10.1002/star.201100077.

22. Panic, V.V.; Madzarevic, Z.P.; Volkov-Husovic, T.; Velickovic, S.J. Poly(methacrylic acid) based hydrogels as adsorbents for removal of cationic dye basic yellow 28: Kinetics, equilibrium study and image analysis. Chemical Engineering Journal 2013, 217, 192-204, https://doi.org/10.1016/j.cej.2012.11.081.

23. Fan, W.W.; Zhang, Z.; Wang, J.C.; Li, Z.G.; Wang, M. Shape memory polyacrylamide/gelatin hydrogel with controllable mechanical and drug release properties potential for wound dressing application. Polymer 2021, 226, 123786, https://doi.org/10.1016/j.polymer.2021.123786.

24. Panic, V.; Adnadjevic, B.; Velikovic, S.; Jovanovic, J. The effects of the synthesis parameters on the xerogels structures and on the swelling parameters of the poly(methacrylic acid) hydrogels. Chemical Engineering Journal 2010, 156, 206-214, https://doi.org/10.1016/j.cej.2009.10.040.

25. Sennakesavan, G.; Mostakhdemin, M.; Dkhar, L.K.; Seyfoddin, A.; Fatihhi, S.J. Acrylic acid/ acrylamide based hydrogels and its properties - A review. Polymer Degradation and Stability 2020, 180, 109308, https://doi.org/10.1016/j.polymdegradstab.2020.109308.

26. Cheng, Y.; Ren, K.; Yang, D.; Wei, J. Bilayer-type fluorescence hydrogels with intelligent response serve as temperature/pH driven soft actuators. Sensors and Actuators B: Chemical 2018, 255, 3117-3126, https://doi.org/10.1016/j.snb.2017.09.137.

27. Okay, O.; Sarışık, S.B. Swelling behavior of poly(acrylamide-co-sodium acrylate)hydrogels in aqueous salt solutions: theory versus experiments. European polymer Journal 2000, 36, 393-399, https://doi.org/10.1016/S0014-3057(99)00058-0.

28. Gemeinhart, R.A.; Park, H.; Park, K. Effect of compression on fast swelling of Poly(acrylamide-co-acrylic acid) superporous hydrogels. Journal of Biomedical Material Research 2001, 55, 54-62, https://doi.org/10.1002/1097-4636(200104)55:1<54::AID-JBM80>3.0.CO;2-Y.

29. Bajpai, S.K.; Johnson, S. Superabsorbent hydrogels for removal of toxic ions. Part I. synthesis and swelling characterization. Reactive and Functional Polymers 2005, 62, 271-283, https://doi.org/10.1016/j.reactfunctpolym.2005.01.002.

30. Bajpai, S.K.; Singh, S. Analysis of swelling behavior of poly(methacrylamide-co-methacrylic acid) hydrogels and effect of the synthesis conditions on water uptake. Reactive and Functional Polymers 2006, 66, 431-440, https://doi.org/10.1016/j.reactfunctpolym.2005.09.003.

31. Liang, C.; Wang, Z.S.; Bruel, C.J. Influence of $\mathrm{pH}$ on persulfate oxidation on TCE at ambient temperature. Chemosphere 2007, 66, 106-113, https://doi.org/10.1016/j.chemosphere.2006.05.026.

32. Bashir, S.; Teo, Y.Y.; Ramesh, S.; Ramesh, K. Synthesis, characterization properties of N-succinyl chitosang-poly(methacrylic acid) hydrogels and in vitro release of theophylline. Polymer 2016, 92, 36-49. https://doi.org/10.1016/j.polymer.2016.03.045.

33. Misra, G.S.; Bhasilal, N.M. Aqueous polymerization of acrylamide by persulfate/thiolactic acid initiator system. European polymer Journal 1978, 14, 901-904, https://doi.org/10.1016/0014-3057(78)90088-5. 
34. Saraç, A.S. Redox polymerization. Progressive Polymer Science 1999, 24, 1149-1204, https://doi.org/10.1016/S0079-6700(99)00026-X.

35. Özeroğlu, C.; Güney, O.; Saraç, A.S.; Mustafaev, M.I. Polymerization of acrylamide initiated with Ce(IV) and $\mathrm{KMnO} 4$ redox system in the presence of glycine. Journal of Applied Polymer Science 1996, 60, 759-765, https://doi.org/10.1002/(SICI)1097-4628(19960502)60:5<759::AID-APP15>3.0.CO;2-U.

36. Özeroğlu, C.; Kurtoğlu, A.E. Synthesis and characterization of acrylamide polymer containing R-(+)-cysteine end groups. European Polymer Journal 2001, 37, 1053-1059, https://doi.org/10.1016/S0014-3057(00)001889.

37. Özeroğlu, C.; Birdal, A. Synthesis and characterization of polyacrylamide containing meso-2,3dimercaptosuccinic acid end groups. Advances in Polymer Technology 2010, 29, 45-53, https://doi.org/10.1002/adv.20180.

38. Pandey, P.K.; Srivastava, A.; Tripathy, J.; Behari, K. Graft copolymerization of acrylic acid onto guar gum initiated by vanadium(V)-mercaptosuccinic acid redox pair. Carbonhydrate Polymer 2006, 65, 414-420, https://doi.org/10.1016/j.carbpol.2006.01.022.

39. Özeroğlu, C.; Sezgin, S. Polymerization of acrylamide initiated with Ce(IV)- and KMNO4-mercaptosuccinic acid redox systems. Express Polymer Letters 2007, 1, 132-141, https://doi.org/10.3144/EXPRESSPOLYMLETT.2007.22.

40. Özeroğlu, C.; İpek, N. Penicillamine-Ce(IV) initiator system for the synthesis of hydrogel containing lithium methacrylate ionic groups. Advances in Polymer Technology 2018, 37, 3305-3314, https://doi.org/10.1002/adv.22115.

41. Ye, T.Z.; Liu, Z.R.; Cai, Z.W. Adsorption of uranium (VI) from aqueous solution by novel dibutyl imide chelating resin. Journal of Radioanalytical Nuclear Chemistry 2020, 323, 223-232, https://doi.org/10.1007/s10967-019-06949-0.

42. Lu, W.; Dai, Z.;Li, L. Liu, J.; Wang, S.; Yang, H.; Cao, C.; Liu, L.; Chen, T.; Zhu, B.; Sun, L.; Chen, L.; Li, H.; Zhang, P. Preparation of composite hydrogel (PCG) and its adsorption performance for uranium(VI). Journal of Molecular Liquids 2020, 303, 112604, https://doi.org/10.1016/j.molliq.2020.112604.

43. Özeroğlu, C.; Keçeli, G. Kinetics of adsorption of strontium ions by a crosslinked copolymer containing methacrylic acid functional groups. Radiochimica Acta 2007, 95, 459-466, https://doi.org/10.1524/ract.2007.95.8.459.

44. Özeroğlu, C.; Bilgiç, Ö.D. Use of the crosslinked copolymer functionalized with acrylic acid for the removal of strontium ions from aqueous solutions. Journal of Radioanalytical and Nuclear Chemistry 2015, 305, 551565, https://doi.org/10.1007/s10967-015-4019-3.

45. Mekewi, M.A.; Madkour, T.M.; Darwish, A.S.; Hashish, Y.M. Does poly(acrylic acid-co-acrylamide) hydrogel by the pluperfect choiceness in the treatment of dyeing waste water? "From simple copolymer of gigantic aqua-waste remover". Journal of Industrial and Engineering Chemistry 2015, 30, 359-371, https://doi.org/10.1016/j.jiec.2015.05.040.

46. Singh, T.; Singhal, R. Regenerable hydrogel based on poly(acrylic acid-sodium acrylate-acrylamide) modified sodium humate for high removal of $\mathrm{Pb} 2+$ and $\mathrm{Fe} 2+$ ions: Metal adsorption kinetics and thermodynamic studies. Desalination and Water Treatment 2014, 52, 5611-5628, https://doi.org/10.1080/19443994.2013.808588.

47. Panic, V.V.; Velikovic, S.J. Removal of model cationic dye by adsorption onto poly(methacrylic acid)/zeolite hydrogel composite: Kinetics, equilibrium study and image analysis. Separation and Purification Technology 2014, 122, 384-394, https://doi.org/10.1016/j.seppur.2013.11.025.

48. Atta, A.M.; Ismail, H.S.; Elsaeed, A.M. Application of anionic polyacrylamide-based hydrogel in the removal of heavy metals from waste water. Journal of Applied Polymer Science 2012, 123, 2500-2510, https://doi.org/10.1002/app.34798.

49. Wang, Y.; Zeng, L.; Ren, X.; Song, H.; Wang, A. Removal of methyl violet from aqueous solution using poly(acrylic acid-co-acrylamide)/attapulgite composite. Journal of Environmental Science 2010, 22, 7-14, https://doi.org/10.1016/S1001-0742(09)60068-1.

50. Vilela, P.B.; Matias, C.A.; Dalalibra, A.; Becegato, V.A.; Paulino, A.T. Polyacrylic acid-based and chitosanbased hydrogels for adsorption of cadmium: Equilibrium isotherm, kinetic and thermodynamic studies. $\begin{array}{llllll}\text { Journal of Environmental Chemical Engineering 2019, 7, 103327, } & \text {, }\end{array}$ https://doi.org/10.1016/j.jece.2019.103327. 
51. Dai, M.Y.; Liu, Y.; Ju, B.Z.; Tian, Y. Preparation thermoresponsive alginate/starch composite hydrogel and its application to the removal of $\mathrm{Cu}$ (II) from aqueous solution. Bioresource Technology 2019, 294, 122192 , https://doi.org/10.1016/j.biortech.2019.122192.

52. Milosevljevic, N.; Dubeljkovic, A.; Krusic, M.K.; Milasinovic, N.; Üzüm, O.B.; Karadağ E. Application of poly(acrylamide-co-sodium methacrylate) hydrogels in copper and cadmium removal from aqueous solution. Environmental Progress and Sustainable Energy 2013, 33, 824-834, https://doi.org/10.1002/ep.11854.

53. Kumar, Y.P.; King, P.; Prasad, V.S.R.K. Equilibrium and kinetic studies for the biosorption system of copper(II) ion from aqueous solution using Tectona grandis L.f. leaves powder. Journal of Hazardous Materials 2006, 137, 1211-1217, https://doi.org/10.1016/j.jhazmat.2006.04.006.

54. Labidi, A.; Salaberria, A.M.; Fernandes, S.C.M.; Labidi, J.; Abderrabba, M. Adsorption of copper on chitinbased materials: Kinetic and thermodynamic studies. Journal of the Taiwan Institute of Chemical Engineers 2016, 65,140-148, https://doi.org/10.1016/j.jtice.2016.04.030.

55. Teow, Y.H.; Kam, L.M.; Mohammad, A.W. Synthesis of cellulose hydrogel for copper (II) ions adsorption. Journal of Environmental Chemical Engineering 2018, 6, 4588-4597, https://doi.org/10.1016/j.jece.2018.07.010.

56. Franson, N.M.; Peppas, N.A. Influence of polymer composition on non-fickian water transport through glassy copolymer. Journal of Applied Polymer Science 1983, 28, 1299-1310, https://doi.org/10.1002/app.1983.070280404.

57. Ritger P.L.; Peppas, N.A. A simple equation for description of solute release II. Fickian and anomalous release from swellable devices. Journal Control Release 1987, 5, 37-42, https://doi.org/10.1016/01683659(87)90035-6.

58. Bıçak, N.; Şenkal, B.F.; Şişmanoğlu, T.; Özeroğlu, C. New, strong cationic hydrogels: Preparation of N,N,N ', N '-tetraallyl piperazinium dibromide and its copolymers with N,N-diallyl morpholinium bromide. Journal of Polymer Science Part A: Polymer Chemistry 2000, 38, 1006-1013, https://doi.org/10.1002/(SICI)10990518(20000315)38:6<1006::AID-POLA10>3.0.CO;2-F.

59. Vigata, M.; Meinert, C.; Huntmacher D.W.; Bock, N. Hydrogels as Drug Delivery Systems: A Review of Current Characterization and Evaluation Techniques. Pharmaceutics 2020, 12, 1188, https://doi.org/10.3390/pharmaceutics12121188.

60. Li, SF.; Zhang, H.; Feng, J.T.; Xu, R.; Liu, XL.; Facile preparation of poly(acrylic acid-acrylamide) hydrogels by frontal polymerization and their use in removal of cationic dyes from aqueous solution. Desalination 2011, 280, 95-102, https://doi.org/10.1016/j.desal.2011.06.056.

61. Craciun, G.; Ighigeanu, D.; Manaila, E.; Stelescu, M.D. Synthesis and characterization of poly(acrylamideco-acrylic acid) flocculant obtained by electron beam irradiation. Materials Research 2015, 18, 984-993. https://doi.org/10.1590/1516-1439.008715.

62. Mohan, Y.M.; Murthy, P.S.K.; Raju, K.M. Synthesis, characterization and effect of reaction parameters on swelling properties of acrylamide-sodium methacrylate superabsorbent copolymers. Reactive and Functional Polymers 2005, 63, 11-26, https://doi.org/10.1016/j.reactfunctpolym.2005.01.005.

63. Özeroğlu, C.; Birdal, A. Swelling properties of acrylamide-N,N'-methylene bis(acrylamide) hydrogels synthesized by using meso-2,3-dimercaptosuccinic acid-cerium(IV) redox couple. Express Polymer Letters 2009, 3, 168-176, https://doi.org/10.3144/expresspolymlett.2009.22.

64. Kumar, K.V.; Sivanesan, S. Pseudo second order kinetics and pseudo isotherms for malachite green onto activated carbon: Comparison of linear and non-linear regression methods. Journal of Hazardous Materials 2006, 136, 721-726, https://doi.org/10.1016/j.jhazmat.2006.01.003.

65. Ho, Y.S. Pseudo-Isotherms Using a Second Order Kinetic Expression Constant. Adsorption 2004, 10, 151158, https://doi.org/10.1023/B:ADSO.0000039870.28835.09. 